Research Article

\title{
Study on the Influence of Baseline Control System on the Fragility of Large-Scale Wind Turbine considering Seismic-Aerodynamic Combination
}

\author{
Chenyang Yuan, ${ }^{1,2}$ Jing $L i \mathbb{D}^{3},{ }^{3}$ Jianyun Chen $\mathbb{D}^{3},{ }^{3,4}$ Qiang Xu $\mathbb{D}^{3},{ }^{3}$ and Yunfei Xie ${ }^{3}$ \\ ${ }^{1}$ School of Water Resources, North China University of Water Resources and Electric Power, Zhengzhou, Henan 450045, China \\ ${ }^{2}$ River and Lake Protection Centro, Ministry of Water Resources the People's Public of China, Beijing 100038, China \\ ${ }^{3}$ Faculty of Infrastructure Engineering, Dalian University of Technology, Dalian, Liaoning 116024, China \\ ${ }^{4}$ State Key Laboratory of Coastal and Offshore Engineering, Dalian University of Technology, Dalian, Liaoning 116024, China
}

Correspondence should be addressed to Jing Li; lijing@dlut.edu.cn

Received 8 September 2019; Revised 5 February 2020; Accepted 18 February 2020; Published 16 April 2020

Academic Editor: Melina Bosco

Copyright (c) 2020 Chenyang Yuan et al. This is an open access article distributed under the Creative Commons Attribution License, which permits unrestricted use, distribution, and reproduction in any medium, provided the original work is properly cited.

\begin{abstract}
The purpose of this paper is to explore the effect of the baseline control system (BCS) on the fragility of large-scale wind turbine when seismic and wind actions are considered simultaneously. The BCS is used to control the power output by regulating rotor speed and blade-pitch angle in real time. In this study, the fragility analysis was performed and compared between two models using different peak ground acceleration, wind speeds, and specified critical levels. The fragility curves with different wind conditions are obtained using the multiple stripe analysis (MSA) method. The calculation results show that the probability of exceedance specified critical level increases as the wind speed increases in model 1 without considering BCS, while does not have an obvious change in the below-rated wind speed range and has a significant decrease in the above-rated wind speed range in model 2 with considering BCS. The comparison depicts that if the BCS is neglected, the fragility of large-scale wind turbine will be underestimated in around the cut-in wind speed range and overestimated in the over-rated wind speed range. It is concluded that the BCS has a great effect on the fragility especially within the operating conditions when the rated wind speed is exceeded, and it should be considered when estimating the fragility of wind turbine subjected to the interaction of seismic and aerodynamic loads.
\end{abstract}

\section{Introduction}

Wind energy has now been a mainstream option for electrical generation because of the continuing exhaustion of fossil fuel and the development of wind turbines, which causes the construction of wind turbines in seismically active areas, such as North America, Japan, and China [1]. Thus, modern wind turbines with large slenderness ratio and flexibility are vulnerable to coupling excitation of seismic and aerodynamic loads, and the International Electrotechnical Commission (IEC) 61400-1 [2] also states that the earthquake shaking should be superposed with operational loading in seismically action regions. For a modern largescale wind turbine, the baseline control system (BCS) is a predominant part, which is used to control the power output by regulating rotor speed and blade-pitch angle in real time. According to the Blade Element Momentum (BEM) theory [3], the rotor speed and blade-pitch angle directly impact the amplitudes of aerodynamic loads of wind turbine. So the loading conditions of wind turbine will be different if the BCS is ignored with constant rotor speed and blade-pitch angle. Furthermore, the reliability analysis becomes more and more important for the safety of wind turbines. Therefore, it seems to be essential to research the influence of the BCS on the fragility of large-scale wind turbine subjected to seismic and aerodynamic loads.

During the designed service life for wind turbines, the major lateral load is wind loading. The structural dynamic responses of a wind turbine subjected to external loads have been studied by many researchers with a number of 
approaches in the last several decades. Naguleswaran [4] simplified the blade to a uniform Euler-Bernoulli beam to investigate its aerodynamic features, which was used by a lot of researchers. With the development of FEM, the method was utilized to investigate the wind-induced dynamic responses of wind turbine tower $[5,6]$. In order to more accurately study the dynamic behaviors of wind turbine, Murtagh et al. [7] and Chen et al. [8] considered the coupling of the blade with the tower/nacelle motion. Gebhardt and Roccia [9] proposed an aeroelastic model to determine the dynamic response of a three-blade wind turbine based on the coupling of a structural model and an aerodynamic model. Page et al. [10] proposed a wind turbine model by following the macroelement approach. Staino and Basu [11] described the dynamics of flexible rotor blades and their interaction with the turbine tower by a multimodal mathematical model. It is significant to find that, in the world, many regions with high potential in wind resources also are high seismic hazard [12-15], for example, the east and south coast of China, the west coast of the United States, and Japan. Prowell et al. [13, 16] conducted a full-scale wind turbine shake table experiment and developed two finite element models to evaluate the seismic response behaviors of a wind turbine, and they found that the significance of taking seismic demand into account increases as the capacity of wind turbines grows. Santangelo et al. [17] investigated a time-domain implementation of uncoupled analyses for seismic assessment of wind turbines in operating conditions. Wang et al. [18] investigated the seismic response of largecapacity wind turbine through a series of centrifuge tests. Wang et al. [19] studied the dynamic responses of offshore wind turbine supported on monopile foundation subjected to wind, wave, and earthquake actions based on the opensource software platform OpenSees. From these studies, it should be noted that although the dynamic responses of wind turbines subjected to seismic-aerodynamic combination have been attracted the attention of many researchers, the rotor speed and blade-pitch angle were assumed constant in many literature studies. In fact, the rotor speed and blade-pitch angle are regulated in real time according to BCS for modern large-scale wind turbines. Therefore, it is important to consider the BCS when accurately researching the dynamic responses of wind turbines with normal operating conditions. Asareh and Prowell [20], Asareh et al. [21], and Asareh et al. [22] investigated the influences of seismicaerodynamic combination for large-scale wind turbines using a computational code FAST (Fatigue, Aerodynamics, Structures, and Turbulence) [23] and found that the interaction will cause that the moment demand value is smaller than the linear addition of the loads. Asareh and Volz [24] used FEM to assess the structural dynamic responses of wind turbines subjected to earthquake and aerodynamic loads and concluded that the pitch control system significantly affects the drag and lift forces applied on blades. Fitzgerald and Basu [25] proposed a monitoring procedure for onshore horizontal axis wind turbines subjected to seismic loading coupled with turbulent aerodynamic loading based on FAST. So the interaction between earthquake and aerodynamic loads during normal operation with BCS is important to accurately analyze the structural dynamic response of wind turbines.

Fragility analysis can provide a measure of the safety margin for the structural system and is considered as the major component of the risk assessment process. More recently, Quilligan et al. [26] compared the relative performance of concrete and steel towers using fragility curves. Kim et al. [27] investigated the seismic fragility curves of offshore wind turbine considering the interaction of nonlinear soil-pile. Atul et al. [28] investigated the seismic fragility curves of a typical wind turbine under the excitation of both near-fault and far-fault ground motions. Mensah and Dueñas-Osorio [29] and Hemmati et al. [30] improved the reliability of wind turbine towers by equipping tuned liquid column dampers (TLCDs). Fitzgerald et al. [31] improved the structural reliability of modern wind turbine towers by equipping active tuned mass dampers (ATMDs). Do et al. [32] pointed out that the fatigue life fragility curves for different average mean wind speeds can be used as design guides for the selection of wind turbine parameters. Mardfekri and Gardoni [33] developed a probabilistic framework to assess the structural performance of offshore wind turbines under multiple hazards. Wilkie and Galasso [34] proposed the use of a probabilistic risk modelling framework to assess the structural risk posed by extreme weather conditions to offshore wind turbines. Avossa et al. [35] presented the preliminary results of a probabilistic framework for the design and assessment of land-based horizontal axis wind turbines subjected to combined wind and seismic actions. del Campo and Pozos-Estrada [36] performed a fragility analysis for a wind turbine structure located in the Southwest of Mexico, taking into consideration wind and earthquake action. Some of these papers have considered the interaction between seismic and aerodynamic loads, but the rotor speed and blade-pitch angle in these papers were fixed. Asareh et al. [37] developed a finite element model and performed the fragility analyses of a 5 MW NREL (National Renewable Energy Laboratory) [38] wind turbine considering the effect of aerodynamic-seismic interaction. Nevertheless, they neglected that the mean wind speed at hub height for the $5 \mathrm{MW}$ wind turbine during normal operation is from 3 (cut-in) to 25 (cut-out) $\mathrm{m} / \mathrm{s}$ and only considered the wind speed from 2.5 to $10 \mathrm{~m} / \mathrm{s}$. Yuan et al. [39] researched the fragility of a $5 \mathrm{MW}$ NREL wind turbine considering the combination of seismic and aerodynamic loads. However, they did not study the effect of BCS on the fragility of wind turbines. From these papers, it can be found that the influence of BCS on the fragility of large-scale wind turbine considering seismic-aerodynamic combination has not been extensively explored yet.

This study explores the influence of BCS on the fragility of large-scale wind turbine considering seismic-aerodynamic combination by comparing the fragility of two computational models. The module developed by Asareh and Prowell [40] is used to compile with the FAST code for consideration of the seismic-aerodynamic combination. The $5 \mathrm{MW}$ NREL wind turbine is also modeled and analyzed with different wind conditions and ground motions. The critical moment and displacement were defined based on pushover analysis and 
ultimate strength analysis in the IEC 61400-1 [2]. The fragility analyses were performed and compared between the two models using different peak ground acceleration (PGA), wind speeds, and specified critical levels.

\section{Computational Models and Basic Theory Description}

The structure of the wind turbine considered in this paper has a shallow foundation and is subjected to seismic and aerodynamic loads. The flowchart of the two computational models is shown in Figure 1. For the first computational model without considering the BCS, the fixed rotor speed and blade-pitch angle are $12.1 \mathrm{rpm}$ and 0 degrees, respectively. For the second model with considering the BCS, the rotor speed and blade-pitch angle will be changing according to the BCS. The aerodynamic loads on the wind turbine blades are always estimated by using the most widely utilized method, the BEM theory $[3,41,42]$. In the theory, coupling blade element theory and momentum theory, the flow and resulting forces on the blade can be determined through balancing axial and angular momentum. According to this theory, if the rotor speed $\Omega$ and blade-pitch angle $\beta_{b}$ vary, the values of aerodynamic loads will change in the same wind condition.

As the requirement of wind energy increases, the installed capacity for one wind turbine increases. The $5 \mathrm{MW}$ NREL wind turbine was used in this paper and the detail structural properties are presented in Table 1. In the process of analysis, the main assumptions are listed in Table 2. The dynamic responses of a $5 \mathrm{MW}$ wind turbine were obtained by modifying the program of FAST and adjusting the input files according to the related information of the turbine $[23,40]$.

2.1. Earthquake Application Model. FAST is an open-source platform [23] and solves a multibody dynamic formulation which is composed of rigid and flexible bodies with limited degrees of freedom (DOFs) for large-scale wind turbines. The equations of motion are derived and implemented according to Kane's dynamics [43]. The blades and tower mode shapes are described by using sixth-order polynomial formulations. In FAST, the nonlinear equation of motion is shown as follows:

$$
\mathbf{M}(\mathbf{q}, \mathbf{u}, t) \ddot{q}+\mathbf{f}\left(\mathbf{q}, \dot{q}, \mathbf{u}, \mathbf{u}_{\mathrm{d}}, t\right)=\mathbf{0},
$$

where $\mathbf{M}$ is the mass matrix; $\mathbf{f}$ is the nonlinear forcing function; $\mathbf{q}$ is the vector of DOF states (and $\dot{q}$ and $\ddot{q}$ are DOF velocities and accelerations); $\mathbf{u}$ is the vector of control inputs; $\mathbf{u}_{\mathrm{d}}$ is the vector of wind inputs; and $t$ is time.

In this study, the ground motions were applied to the base of the support structure by using an improved module implemented by Asareh and Prowell [40]. The improved seismic module has been verified to be in good agreement with experiments [44], which is used by many researchers $[21,22]$. During the process of running the developed FAST program, the degree of freedom at the base of the tower in the desired direction is released first and then replaced by a damped actuator with stiffness $k_{\text {act }}$ and damping $c_{\text {act }}$ properties given in equations (2) and (3). At each time step, the seismic force $F_{\text {act }}$ transformed from ground accelerations by the damped actuator for the desired direction is expressed in equation (4):

$$
\begin{aligned}
& k_{\mathrm{act}}=m_{\mathrm{tol}}\left(2 \pi f_{\mathrm{act}}\right)^{2}, \\
& c_{\mathrm{act}}=2 m_{\mathrm{tol}} \xi_{\mathrm{act}}\left(2 \pi f_{\mathrm{act}}\right), \\
& F_{\mathrm{act}}=k_{\mathrm{act}}(x-d)+c_{\mathrm{act}}\left(x_{v}-v\right),
\end{aligned}
$$

where $x$ and $x_{\mathrm{v}}$ are the desired displacement and velocity of the tower base, $d$ and $v$ are the realized displacement and velocity, $m_{\text {tol }}$ is the total mass of the wind turbine and platform, $f_{\text {act }}$ is the actuator frequency, and $\xi_{\text {act }}$ is the actuator damping ratio.

The interaction of seismic and aerodynamic loads can be taken into account based on the developed FAST program. Based on equation (1), the second-order linearized representation of the equation [23] about the operating point (op) can be obtained by expanding as a Taylor series approximation [39]:

$$
\mathbf{M} \ddot{q}+\mathbf{C} \dot{q}+\mathbf{K q}=\mathbf{F u}+\mathbf{F}_{\mathrm{d}} \mathbf{u}_{\mathrm{d}}+\mathbf{F}_{\mathrm{e}}
$$

where $\mathbf{M}=\left.\mathbf{M}\right|_{\text {op }}$ is the mass matrix; $\mathbf{C}=\partial \mathbf{f} /\left.\partial \dot{q}\right|_{\text {op }}$ is the damping matrix; $\mathbf{K}=\left.[(\partial \mathbf{M} / \partial \mathbf{q}) \ddot{q}+(\partial \mathbf{f} / \partial \mathbf{q})]\right|_{\mathrm{op}}$ is the stiffness matrix; $\mathbf{F}=-\left.[(\partial \mathbf{M} / \partial \mathbf{u}) \ddot{q}+(\partial \mathbf{f} / \partial \mathbf{u})]\right|_{\text {op }}$ is the control input matrix; $\mathbf{F}_{\mathrm{d}}=-\partial \mathbf{f} /\left.\partial \mathbf{u}_{\mathrm{d}}\right|_{\text {op }}$ is the wind input matrix; and $\mathbf{F}_{\mathrm{e}}$ is the vector of seismic load formed according to $F_{\text {act }}$.

2.2. BCS Description. For wind turbines, the major target of the BCS is to control the power production in different wind conditions by regulating rotor speed and blade-pitch angle. The BCS is always composed of two control systems: a generator-torque controller and a blade-pitch controller [38]. Figure 2 presents a schematic representation of BCS. The generator speed measurement is used as the feedback input for the generator-torque and blade-pitch controllers. A recursive, single-pole low-pass filter with exponential smoothing is used to filter the generator speed measurement [38].

When the wind speed is lower than the rated wind speed, for the most part, the generator-torque works. In this region, the goal is to maximize power capture and the mechanical power $P$ is shown as follows:

$$
P=\frac{1}{2} \rho A C_{p} v^{3},
$$

where $\rho$ is the density of the air, $A$ is the cross-sectional area of the rotor, $C_{p}$ is the power coefficient, and $v$ is the wind speed. The relation between the generator torque $T_{g}$ and speed $w_{g}$ can be expressed as follows [45]:

$$
T_{g}=K_{g} w_{g}{ }^{2},
$$

and

$$
\begin{aligned}
& K_{g}=\frac{1}{N_{g}^{3}} \frac{1}{2} \rho \pi R^{5} \frac{C_{p \max }}{\left(\lambda_{\mathrm{opt}}\right)^{3}}, \\
& w_{g}=N_{g} \Omega,
\end{aligned}
$$



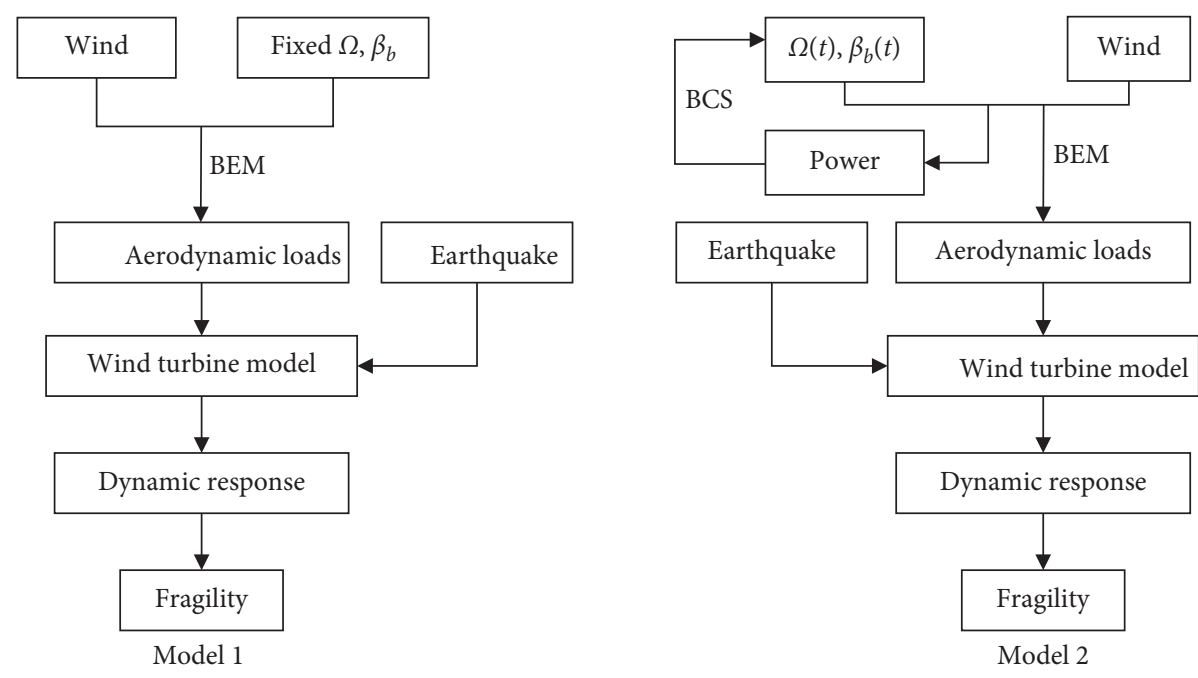

FIgURE 1: Flowchart of the two computational models.

TABLE 1: Properties of 5 MW NREL wind turbine [38].

\begin{tabular}{lc}
\hline $5 \mathrm{MW}$ NREL baseline wind turbine properties \\
\hline $\begin{array}{l}\text { Rating } \\
\text { Rotor }\end{array}$ & $5 \mathrm{MW}$ \\
$\begin{array}{l}\text { orientation, } \\
\text { configuration }\end{array}$ & Upwind, 3 blades \\
$\begin{array}{l}\text { Control } \\
\text { Rotor and hub }\end{array}$ & Variable speed, collective pitch \\
diameters & $126 \mathrm{~m}$ and $3 \mathrm{~m}$ \\
Hub height & $90 \mathrm{~m}$ \\
Cut-in, rated, and & \\
cut-out wind & \\
speed & $3 \mathrm{~m} / \mathrm{s}, 1.4 \mathrm{~m} / \mathrm{s}$, and $25 \mathrm{~m} / \mathrm{s}$ \\
Cut-in and rated & \\
rotor speed & \\
Rated tip speed & $6.9 \mathrm{rpm}$ and $12.2 \mathrm{rpm}$ \\
Blade length & $80 \mathrm{~m} / \mathrm{s}$ \\
Blade mass & $61.5 \mathrm{~m}$ \\
Hub mass & $17740 \mathrm{~kg}$ \\
Nacelle mass & $56780 \mathrm{~kg}$ \\
Tower above & $240000 \mathrm{~kg}$ \\
ground height & $87.6 \mathrm{~m}$ \\
Tower mass & $347460 \mathrm{~kg}$ \\
\hline
\end{tabular}

where $N_{g}$ is the gearbox ratio, $R$ is the rotor radius, $C_{p \max }$ is the maximum power coefficient, and $\lambda_{\text {opt }}$ is the optimum tipspeed ratio.

When the wind speed exceeds the rated wind speed, for the most part, the blade-pitch controller works. In this region, the proportional-integral-derivative (PID) control on the speed error between the filtered generator speed and the rated generator speed was used to regulate the pitch angle of the blade [38]. The related equation is shown as follows:

$$
\Delta \beta_{b}=K_{P} N_{g} \Delta \Omega+K_{I} \int_{0}^{t} N_{g} \Delta \Omega d t+K_{D} N_{g} \frac{d(\Delta \Omega)}{d t},
$$

where $\Delta \beta_{b}$ is the small perturbation of blade-pitch angle about its operating point, $\Delta \Omega$ is the small perturbation of rotor speed about the rated rotor speed, and $K_{P}, K_{I}$, and $K_{D}$ are the proportional, integral, and derivative gains, respectively.

In this paper, according to the recommendation by Hansen et al. [46], neglecting the derivative gain and negative damping, the $K_{P}$ and $K_{I}$ are shown as follows:

$$
\begin{gathered}
K_{P}\left(\beta_{b}\right)=\frac{2 I_{\text {Drive }} \Omega_{0} \xi_{\varphi} \omega_{\varphi}}{N_{g}\left(-\left(\partial P / \partial \beta_{b}\right)\left(\beta_{b}=0\right)\right)} G K\left(\beta_{b}\right), \\
K_{I}\left(\beta_{b}\right)=\frac{I_{\text {Drive }} \Omega_{0} \omega_{\varphi}^{2}}{N_{g}\left(-\left(\partial P / \partial \beta_{b}\right)\left(\beta_{b}=0\right)\right)} G K\left(\beta_{b}\right),
\end{gathered}
$$

where $I_{\text {Drive }}$ is the drivetrain inertia cast to the low-speed shaft, $\Omega_{0}$ is the rated rotor speed, $\omega_{\varphi}$ and $\xi_{\varphi}$ are the natural frequency and damping ratio of the simplified equation of motion for the rotor speed error [38], $G K\left(\beta_{b}\right)$ is the dimensionless gain-correction factor (from [46]), and $\partial P / \partial \beta_{b}$ is the blade-pitch sensitivity. More details about calculating the proportional and integral gains can be found in [38].

2.3. Fragility Estimation. The seismic fragility curves describe the probability of selected structure responses exceedance some limit state of interest to intensity measure (IM) of seismic excitations such as PGA or the spectral acceleration for the natural period $\left(S_{\mathrm{a}}\right)$. PGA is used in this paper. Assuming that the distribution of PGA/ $S_{\mathrm{a}}$ corresponding to a specified critical level of the selected structure is a lognormal distribution [37] which is usually utilized to obtain fragility curves. According to the assumption, the fragility function can be expressed as follows:

$$
P(C \mid P G A=y)=\Phi\left(\frac{\ln \left(y / \theta_{y}\right)}{\beta_{y}}\right),
$$

where $P(C \mid P G A=y)$ is the probability that an earthquake with $P G A=y$ will result in the selected structure to exceed 
TABLE 2: Main assumptions.

\begin{tabular}{ll}
\hline Models & Assumptions \\
\hline \multirow{2}{*}{ Wind turbine model } & (1) The foundation, nacelle, hub, and gears are rigid [23] \\
& (2) The blades, tower, and drive shaft are flexible [23] \\
(1) There are no aerodynamic interactions between different elements [41] & (2) The forces acting on each element only depend on the drag and lift characteristics of the airfoil shape of the \\
beM model & blades [41]
\end{tabular}

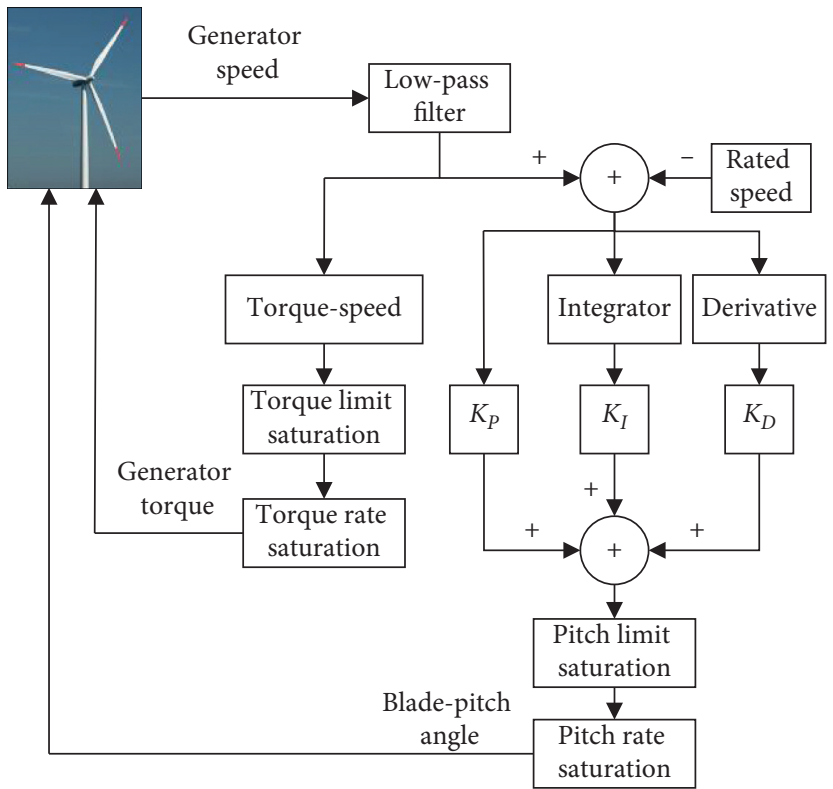

FIgURE 2: The schematic representation of BCS.

the specified critical level, $\Phi$ is the standard normal cumulative distribution function, $\theta_{y}$ is the median of the fragility function, and $\beta_{y}$ is the standard deviation of $\ln P G A$. According to the above formula, estimation of $\theta_{y}$ and $\beta_{y}$ from the structural analysis is required to generate fragility function curves.

There are various procedures for estimating $\theta_{y}$ and $\beta_{y}$, for example, incremental dynamic analysis (IDA) [47] and multiple stripe analysis (MSA) [48]. For MSA, a group of ground motions with a specified selection of IM levels are used and the exceedance specified critical level probability for each IM level is estimated by performing structural analyses. Furthermore, Baker [48] concluded that the MSA can produce more effective fragility parameter estimates than the IDA with a limited number of structure responses, and it is less computationally expensive [30]. Therefore, the method of MSA is used to estimate fragility parameters in this study. The maximum likelihood approach is used to construct fragility curves. Assuming that the observation of exceedance or not exceedance specified critical level for a given ground motion is independent of that of other earthquakes, the probability of $z_{i}$ exceedance specified critical level out of $n_{i}$ ground motions with PGA $=y_{i}$ can be defined by the binomial distribution:

$$
\begin{aligned}
& P\left(z_{i} \text { exceedance critical level in } n_{i} \text { ground motions }\right)=\left(\begin{array}{c}
n_{i} \\
z_{i}
\end{array}\right) p_{i}^{z_{i}}\left(1-p_{i}\right)^{n_{i}-z_{i}}, \\
& \text { that a ground motion with PGA }=\quad L_{f}=\Pi_{i=1}^{q}\left(\begin{array}{c}
n_{i} \\
z_{i}
\end{array}\right) p_{i}^{z_{i}}\left(1-p_{i}\right)^{n_{i}-z_{i}},
\end{aligned}
$$

where $p_{i}$ is the probability that a ground motion with PGA $=$ $y_{i}$ will exceed the specified critical level.

The aim is to identify the fragility function that predicts $p_{i}$ with the highest probability of having observed the exceedance specified critical level data acquired from structural analysis. The product of the binomial probabilities can be taken from equation (12) at each IM level to obtain the likelihood $L_{f}$ : where $q$ is the number of PGA levels and $\Pi$ is a product over all levels. By substituting equation (11) into (13), the likelihood function can be defined as follows: 


$$
L_{f}=\Pi_{i=1}^{q}\left(\begin{array}{c}
n_{i} \\
z_{i}
\end{array}\right) \Phi\left(\frac{\ln \left(y_{i} / \theta_{y}\right)}{\beta_{y}}\right)^{z_{i}}\left[1-\Phi\left(\frac{\ln \left(y_{i} / \theta_{y}\right)}{\beta_{y}}\right)\right]^{n_{i}-z_{i}} .
$$

The fragility function parameters $\theta_{y}$ and $\beta_{y}$ can be estimated by maximizing this likelihood function. The optimization solver in MATLAB was used to obtain the estimated parameters. Maximizing the logarithm of the likelihood function is equivalent and numerically easier, so the related function is shown in the following equation:

$$
\begin{aligned}
\left\{\widehat{\theta}_{y}, \widehat{\beta}_{y}\right\}= & \underset{\theta_{y}, \beta_{y}}{\arg \max } \sum_{i=1}^{q}\left\{\ln \left(\begin{array}{c}
n_{i} \\
z_{i}
\end{array}\right)+z_{i} \ln \Phi\left(\frac{\ln \left(y_{i} / \theta_{y}\right)}{\beta_{y}}\right)\right. \\
& \left.+\left(n_{i}-z_{i}\right) \ln \left[1-\Phi\left(\frac{\ln \left(y_{i} / \theta_{y}\right)}{\beta_{y}}\right)\right]\right\} .
\end{aligned}
$$

The fragility function can be obtained using this approach.

\section{Excitation Loads and Specified Critical Levels}

3.1. Wind Loading. According to the IEC 61400-1 [2], the turbulence wind models are generated based on the turbulence intensity $I$ and the mean wind speed at hub height $V_{\text {hub }}$. The mean wind speed at different height $V(z)$ and the turbulence intensity $I$ are expressed as follows [2]:

$$
\begin{aligned}
V(z) & =V_{\text {hub }}\left(\frac{z}{z_{\text {hub }}}\right)^{\alpha}, \\
I & =\frac{\sigma}{V_{\text {hub }}},
\end{aligned}
$$

and

$$
\sigma=I_{\text {ref }}\left(0.75 V_{\text {hub }}+5.6\right),
$$

where $z$ is the height above the ground, $\alpha$ is the power law exponent (assumed to be 0.2), $\sigma$ is the turbulence standard deviation, and $I_{\text {ref }}$ is the turbulence intensity when the wind speed is $15 \mathrm{~m} / \mathrm{s}$.

A set of 12 wind files in time during of $600 \mathrm{~s}$ with different $V_{\text {hub }}$ from $3 \mathrm{~m} / \mathrm{s}$ to $25 \mathrm{~m} / \mathrm{s}$ were simulated by using the program TurbSim [49] and then used as the input files in the calculation program of FAST. According to equations (16) and (18), the distribution of each normal mean wind speed with different height and turbulence intensity with different $V_{\text {hub }}$ are shown in Figures 3 and 4, respectively.

3.2. Ground Motions. In China, there are rich wind resources and the Taiwan Strait off the coast of Fujian is found to have the strongest wind speeds [14]. Furthermore, the site class in Fujian is II [50], which means that wind turbines in Fujian have opportunity to suffer the coupling excitation of seismic and aerodynamic loads. For ground motion selection, the magnitude-distance-soil condition triads should be

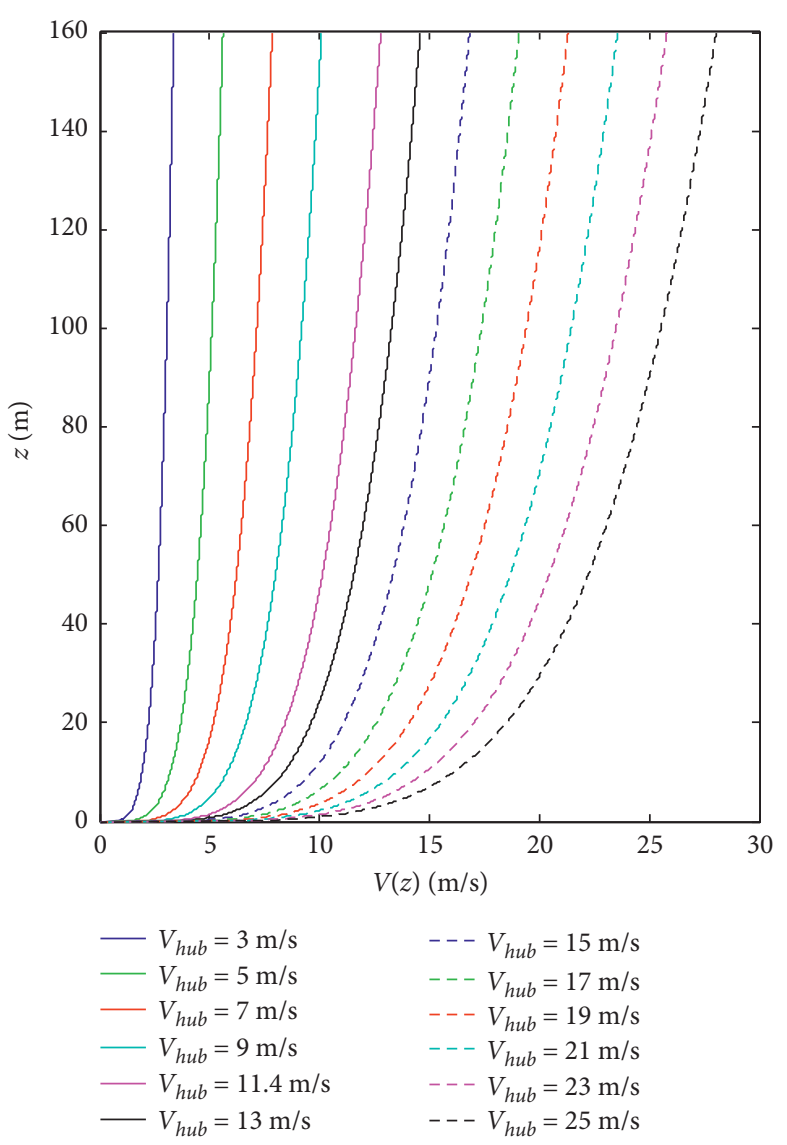

FIGURE 3: The distribution of normal mean wind speed with different height.

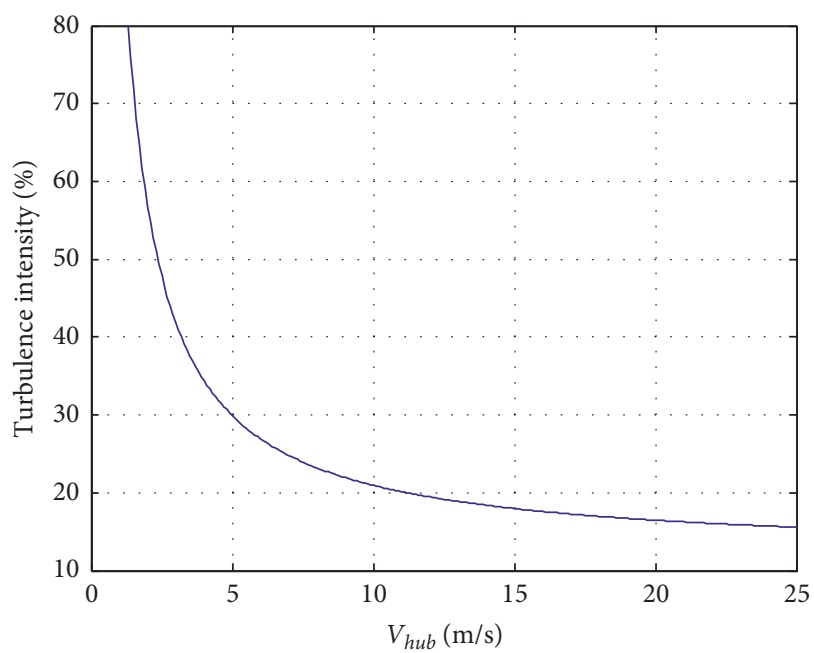

FIgURE 4: Turbulence intensity with different $V_{\text {hub }}$.

considered. There are uncertainties in magnitude and distance calculations, so it is reasonable to select earthquake records within appropriate ranges. The guideline pointed out by Elnashai and Di Sarno [51] states that it is reasonable to search within a range of \pm 0.3 magnitude units and $\pm 20-40 \mathrm{~km}$ distance. The general consensus is to select ground motions so their magnitude and distance are within 
TABLE 3: Selected record characteristics.

\begin{tabular}{|c|c|c|c|c|c|c|}
\hline No. & Event & Year & Station & Magnitude & $R(\mathrm{~km})$ & $V_{\mathrm{s}} 30(\mathrm{~m} / \mathrm{s})$ \\
\hline 1 & San Fernando & 1971 & Wheeler Ridge-Ground & 6.6 & 70.23 & 347.67 \\
\hline 2 & San Fernando & 1971 & Whittier Narrows Dam & 6.6 & 39.45 & 298.68 \\
\hline 3 & Imperial Valley-06 & 1979 & Coachella Canal \#4 & 6.5 & 50.10 & 336.49 \\
\hline 4 & Irpinia_Italy-02 & 1980 & Bovino & 6.2 & 43.50 & 356.39 \\
\hline 5 & Coalinga-01 & 1983 & Parkfield-Cholame 12W & 6.4 & 55.77 & 359.03 \\
\hline 6 & Coalinga-01 & 1983 & Parkfield-Cholame 1E & 6.4 & 43.68 & 326.64 \\
\hline 7 & Coalinga-01 & 1983 & Parkfield-Cholame 4AW & 6.4 & 47.57 & 283.38 \\
\hline 8 & Coalinga-01 & 1983 & Parkfield_Cholame 4W & 6.4 & 46.35 & 410.40 \\
\hline 9 & Coalinga-01 & 1983 & Parkfield-Cholame 6W & 6.4 & 50.20 & 251.57 \\
\hline 10 & Coalinga-01 & 1983 & Parkfield-Cholame 8W & 6.4 & 51.75 & 256.82 \\
\hline 11 & Coalinga-01 & 1983 & Parkfield-Fault Zone 10 & 6.4 & 31.62 & 372.73 \\
\hline 12 & Coalinga-01 & 1983 & Parkfield-Fault Zone 2 & 6.4 & 38.95 & 294.26 \\
\hline 13 & Coalinga-01 & 1983 & Parkfield-Fault Zone 6 & 6.4 & 32.87 & 266.65 \\
\hline 14 & Coalinga-01 & 1983 & Parkfield-Fault Zone 9 & 6.4 & 31.71 & 372.26 \\
\hline 15 & Coalinga-01 & 1983 & Parkfield-Gold Hill 2E & 6.4 & 33.07 & 360.92 \\
\hline 16 & Coalinga-01 & 1983 & Parkfield-Gold Hill 2W & 6.4 & 37.02 & 290.50 \\
\hline 17 & Coalinga-01 & 1983 & Parkfield-Gold Hill 4W & 6.4 & 41.10 & 421.20 \\
\hline 18 & Coalinga-01 & 1983 & Parkfield-Vineyard Cany 3W & 6.4 & 32.17 & 308.87 \\
\hline 19 & Morgan Hill & 1984 & Capitola & 6.2 & 39.08 & 288.62 \\
\hline 20 & Morgan Hill & 1984 & Fremont-Mission San Jose & 6.2 & 31.34 & 367.57 \\
\hline 21 & Morgan Hill & 1984 & Los Banos & 6.2 & 63.16 & 262.05 \\
\hline 22 & Taiwan SMART1(40) & 1986 & SMART1 O01 & 6.3 & 61.97 & 267.67 \\
\hline 23 & N. Palm Springs & 1986 & Hemet Fire Station & 6.1 & 34.71 & 328.09 \\
\hline 24 & N. Palm Springs & 1986 & Indio & 6.1 & 35.57 & 307.54 \\
\hline 25 & N. Palm Springs & 1986 & Indio_Coachella Canal & 6.1 & 41.93 & 339.02 \\
\hline 26 & N. Palm Springs & 1986 & Landers Fire Station & 6.1 & 35.36 & 331.02 \\
\hline 27 & N. Palm Springs & 1986 & San Jacinto Valley Cemetery & 6.1 & 30.97 & 330.74 \\
\hline 28 & N. Palm Springs & 1986 & Winchester Page Bros R & 6.1 & 38.22 & 287.87 \\
\hline 29 & Whittier Narrows-01 & 1987 & Arleta-Nordhoff Fire Sta & 6.0 & 36.97 & 297.71 \\
\hline 30 & Whittier Narrows-01 & 1987 & Canoga Park-Topanga Can & 6.0 & 48.96 & 267.49 \\
\hline 31 & Whittier Narrows-01 & 1987 & Canyon Country-W Lost Cany & 6.0 & 48.18 & 325.60 \\
\hline 32 & Whittier Narrows-01 & 1987 & Featherly Park-Maint & 6.0 & 37.92 & 367.54 \\
\hline 33 & Whittier Narrows-01 & 1987 & Fountain Valley_Euclid & 6.0 & 39.45 & 270.54 \\
\hline 34 & Whittier Narrows-01 & 1987 & Huntington Beach-Lake St & 6.0 & 44.58 & 315.52 \\
\hline 35 & Whittier Narrows-01 & 1987 & LB-Recreation Park & 6.0 & 33.68 & 282.00 \\
\hline 36 & Whittier Narrows-01 & 1987 & Lancaster-Med Off FF & 6.0 & 67.62 & 339.14 \\
\hline 37 & Whittier Narrows-01 & 1987 & Leona valley \#6 & 6.0 & 59.60 & 327.44 \\
\hline 38 & Whittier Narrows-01 & 1987 & Malibu-Point Dume Sch & 6.0 & 63.23 & 349.54 \\
\hline 39 & Whittier Narrows-01 & 1987 & Newhall-Fire Sta & 6.0 & 52.20 & 269.14 \\
\hline 40 & Whittier Narrows-01 & 1987 & Newhall-W Pico Canyon Rd. & 6.0 & 58.61 & 285.93 \\
\hline 41 & Whittier Narrows-01 & 1987 & Pacoima Kagel Canyon USC & 6.0 & 36.29 & 323.76 \\
\hline 42 & Whittier Narrows-01 & 1987 & Panorama City_Roscoe & 6.0 & 36.55 & 318.16 \\
\hline 43 & Whittier Narrows-01 & 1987 & Sun Valley-Roscoe Blvd & 6.0 & 34.99 & 320.93 \\
\hline 44 & Whittier Narrows-01 & 1987 & Sylmar-Sayre st & 6.0 & 40.61 & 348.87 \\
\hline 45 & Whittier Narrows-01 & 1987 & Terminal Island-S Seaside & 6.0 & 40.36 & 260.60 \\
\hline 46 & Whittier Narrows-01 & 1987 & Torrance-W 226th St & 6.0 & 36.11 & 289.04 \\
\hline 47 & Big Bear-01 & 1992 & Hesperia-4th \& Palm & 6.5 & 44.65 & 358.36 \\
\hline 48 & Big Bear-01 & 1992 & Indio-Riverside Co. Fairgrounds & 6.5 & 78.21 & 282.14 \\
\hline 49 & Big Bear-01 & 1992 & San Bernardino-2nd and Arrowhead & 6.5 & 33.79 & 325.83 \\
\hline 50 & Big Bear-01 & 1992 & San Bernardino-E and Hospitality & 6.5 & 35.20 & 296.97 \\
\hline
\end{tabular}

Note. $R$ : closest site-to-fault-rupture distance; $V_{s} 30$ : shear wave velocity.

a close range of the target scenario magnitude and distance. Based on the design response spectra of Fujian area [50] and the guideline [51], a total of 50 ground motion records are selected within the calculated magnitude range of 6.0-6.6 and a distance range between 30.97 and $78.21 \mathrm{~km}$ from strong motion database of Pacific Earthquake Engineering Research Center (PEER) [52], and the characteristics of selected earthquake records are summarized in Table 3.
According to the study by Hancock et al. [53], this paper matched the response spectra of selected records for periods ranging from $0.2 \mathrm{~T}$ to $1.5 \mathrm{~T}$ with the target spectrum [54], where $T$ is the natural period of the structure in the fundamental mode for the direction of the response being analyzed. As the first fore-aft (FA) mode frequency is $0.324 \mathrm{~Hz}$ and the related $T$ is $3.1 \mathrm{~s}$ [38], therefore the period range of interest is calculated from $0.2 T=0.62 \mathrm{~s}$ to 


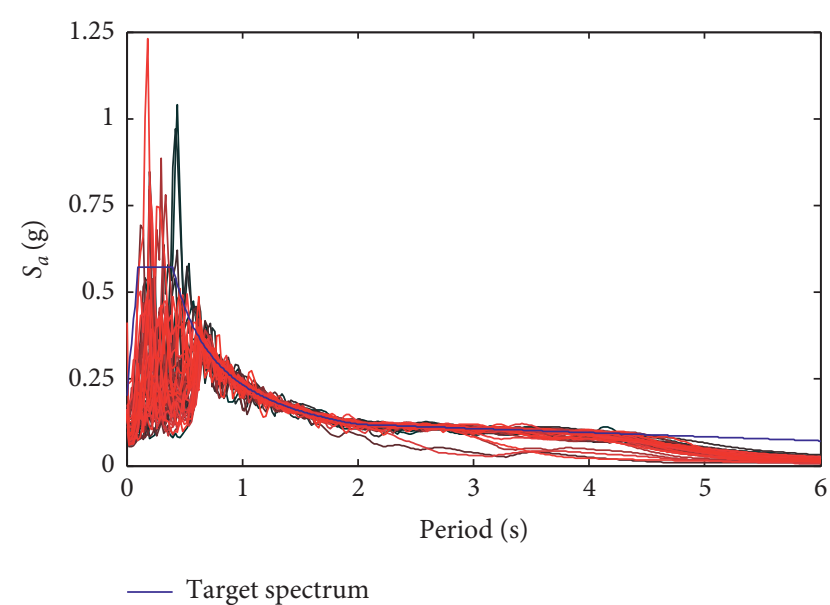

FIGURE 5: Spectrally matched spectra and target spectrum.

$1.5 T=4.65$ s. Finally, all the records were matched by using the SeismoMatch version 2.1.2 [55], and the matched spectra and target spectrum are shown in Figure 5.

3.3. Specified Critical Levels. In order to evaluate wind turbine safety under external excitations, the critical levels should be defined according to structural responses. For a wind turbine, the relationship of maximum displacement at the tower top and the maximum stress at the tower base is one-to-one subjected to simple loading conditions, and the critical displacement at tower top can be defined by using static pushover analysis [27]. In this paper, we defined the critical levels based on IEC 61400-1 [2] and static pushover analysis.

According to IEC 61400-1 [2], the limit state function for wind turbine can be expressed as follows:

$$
\gamma_{n} S \leq R_{s}
$$

and

$$
f_{d}=\frac{1}{\gamma_{m}} f_{k},
$$

where $\gamma_{n}$ is the consequence of failure factor, $f_{d}$ is the design value for material, $\gamma_{m}$ is the partial safety factor for material, $f_{k}$ is the characteristic value of material properties, $S$ is the highest stress value of the structural response, and $R_{s}$ is the maximum allowable design value of material resistance, hence $R_{s}=f_{d}$. In this paper, $\gamma_{n}$ is $1.0, \gamma_{m}$ is 1.2 , and $f_{k}$ is $408 \mathrm{MPa}$ (yield stress of steel) [27].

Based on the analysis in $[21,22]$, the position of maximum tower moment under the earthquake excitation is the tower base. The maximum stress $\sigma_{\max }$ on a circular hollow section under the moment $M$ can be shown as follows:

$$
M=\sigma_{\max } W
$$

and

$$
W=\frac{\pi D_{0}^{3}}{32}\left[1-\left(1-\frac{2 n_{t}}{D_{0}}\right)^{4}\right],
$$

where $D_{0}$ is the outer diameter of the circular hollow section and $n_{t}$ is the thickness of the circular hollow section.

In order to find the critical levels, static pushover analysis $[27,56]$ is proposed based on a simplified wind turbine model in finite element analysis software. The blade and tower are modeled according to the geometric properties using beam elements, which is consistent with the structural properties of wind turbine in [38]. For the tower, Young's modulus is $210 \mathrm{GPa}$, Poisson ratio is 0.3 , density is $7850 \mathrm{~kg} / \mathrm{m}^{3}$, and yield stress is $408 \mathrm{MPa}$. The buckling limit state condition is not explicitly taken into account within the structural model of the tower. By applying a horizontal displacement load with an incremental increase in the FA direction to the reference point of the rigid nacelle, the relation between the nacelle displacement and tower base stress was obtained and is shown in Figure 6. From the figure, it can be found the critical displacement at the limit and yield state. According to equations (21) and (22), the related critical tower base moment can be obtained. The tower base moment and tower top displacement for the limit and yield state are defined as the critical levels. The detailed values of tower top displacement $(D)$ and tower base moment $(M)$ in limit $(L)$ and yield $(Y)$ state can be obtained according to the pushover curve and are shown in Table 4.

\section{Simulation Results and Fragility Analysis}

The 50 earthquake ground motions are scaled to a discrete set of PGA levels ranging from $0.1 \mathrm{~g}$ to $1.0 \mathrm{~g}$. For each wind condition, the demand of wind turbine over the range of PGA values can be obtained based on MSA by scattering multiple stripes of PGA [57]. During the simulation of $600 \mathrm{~s}$, the ground motions were applied at $400 \mathrm{~s}$. Then, according to the simulation results, the related fragility curves for each wind condition were obtained based on equations (13) and (17).

4.1. Comparison of Simulation Results. During normal operation (for model 2), the rotor speed and/or blade-pitch angle will keep changing with the variation of wind speed based on BCS, which results in the change of aerodynamic loads, and then affect the combination of seismic and aerodynamic loads. This is the main difference between the two computational models, which will lead to different dynamic responses of wind turbine under the excitation of seismic-aerodynamic combination.

According to equation (15), it can be known that it is significant for fragility estimation to obtain the number of ground motions caused by the maximum responses of wind turbine exceedance specified critical levels in each seismic level. Figures 7 and 8 show the statistical data for different wind speeds and PGA as a three-dimensional histogram in model 1 and model 2, respectively. It is noted that when the values of PGA and wind speed are relatively small, the related number is zero, and only when the values of PGA and wind speed surpass certain values, the maximum dynamic responses of wind turbine will exceed the specified critical levels. It is also found that, for each wind speed condition in 


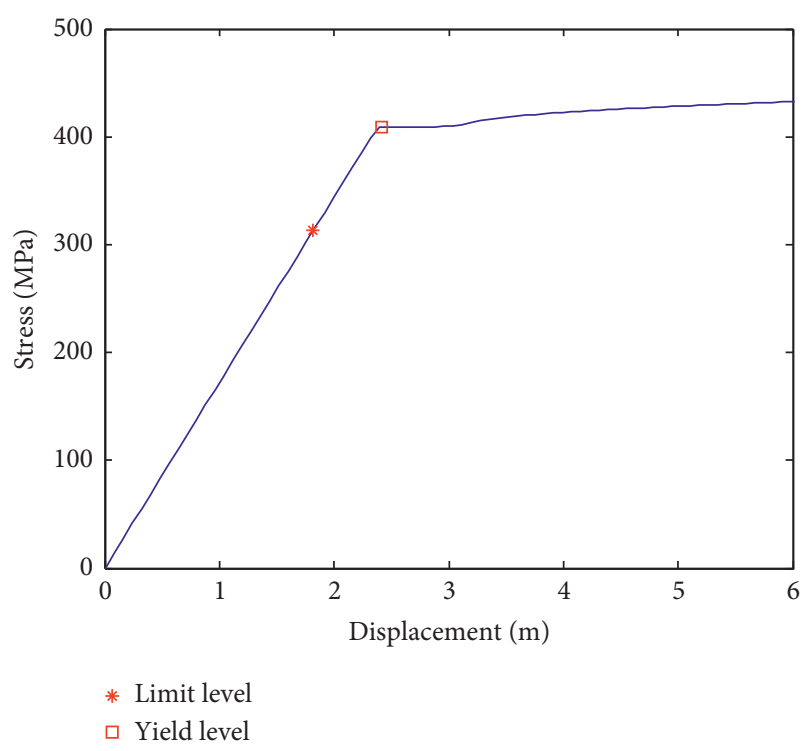

FIGURE 6: Relation between the nacelle displacement and tower base stress from static pushover analysis.

TABLe 4: Specified critical levels.

\begin{tabular}{lc}
\hline Case & Critical level \\
\hline Displacement at yield (DY) & $2.418 \mathrm{~m}$ \\
Displacement at limit (DL) & $1.817 \mathrm{~m}$ \\
Moment at yield (MY) & $3.07000 \times 10^{5} \mathrm{kN} \cdot \mathrm{m}$ \\
Moment at limit (ML) & $2.28845 \times 10^{5} \mathrm{kN} \cdot \mathrm{m}$ \\
\hline
\end{tabular}

one specified critical level in each model, the exceedance number increases with the increase of the PGA level. The ML is the first critical level to be exceeded and then MY, DL, and DY. It can be seen from Figure 7 that the exceedance number increases as the wind speed increases with the same PGA level for MY, and the same trend occurs for ML, DY, and DL. However, in Figure 8, the exceeding number does not have an obvious change in the below-rated wind speed range and then has a large decrease in the above-rated wind speed range for the four specified critical levels. The main reason for this phenomenon is that the increase of blade-pitch angle caused by the BCS results in aerodynamic load decrease in the FA direction when the wind speed exceeds the rated wind speed. As presented, the BCS may reduce the dynamic responses of wind turbine subjected to the excitation of seismic-aerodynamic combination in model 2 compared to model 1 . By comparing the exceedance number in each wind and PGA level between the two models, it can be concluded that the BCS has an obvious influence on the results of dynamic responses especially in the above-rated wind speed range.

4.2. Comparison of Fragility Function Parameters. Based on equation (17), the fragility parameters $\theta$ and $\beta$ in different wind scenarios can be estimated. The variations of the two parameters with different wind speeds are investigated and compared between the two models. Figures 9 and 10 show the comparison of the estimated $\theta$ and $\beta$ with different wind speeds between the two models for specified critical levels, respectively. From Figure 9, it can be found that the value of estimated $\theta$ decreases with the increase of wind speed in model 1. It also can be found that the parameter $\theta$ in model 2 is less than that in model 1 when the wind speed is cut-in wind speed, has almost identical values with that in model 1 when the wind speed is larger than cut-in and less than the rated wind speed, and is larger than that in model 1 when the wind speed ranges from rated to cut-out wind speed. Furthermore, the value of estimated $\theta$ has a significant increase when the wind speed is from $9 \mathrm{~m} / \mathrm{s}$ to $11.4 \mathrm{~m} / \mathrm{s}$, but the variation trend is not obvious when the wind speed exceeds the rated wind speed. Figure 10 demonstrates that the variation trend of the estimated $\beta$ for the four specified critical levels increases along with the wind speed increase as a whole in model 1, but decrease along with the wind speed increase as a whole in model 2. It can be seen from Figure 10(a) the parameter $\beta$ in model 2 is slightly larger than that in model 1 when the wind speed is less than $9 \mathrm{~m} / \mathrm{s}$ and is less than that in model 1 when the wind speed is larger than $9 \mathrm{~m} / \mathrm{s}$ with the difference between the two models increasing as the wind speed increases in this wind range. It is noted that the variation trend of the estimated $\beta$ for both models in Figures $10(\mathrm{~b})-10(\mathrm{~d})$ is similar to that in Figure 10(a) when the wind speed is larger than $9 \mathrm{~m} / \mathrm{s}$ and has a slight difference with that in Figure 10(a) when the wind speed is less than $9 \mathrm{~m} / \mathrm{s}$, but the phenomenon that the $\beta$ in model 2 is larger than that in model 1 when the wind speed is cut-in wind speed is similar with that in Figure 10(a). These results show that the influence of the BCS on the estimation of fragility function parameters increases with the increase of wind speed. From the analysis of comparison in fragility function parameters, it is concluded that the estimated values of $\theta$ and $\beta$ have an obvious difference between the two computational models due to the difference in the coupling effect of seismic and aerodynamic loads.

4.3. Comparison of Fragility Curves. According to equation (11) and the estimated fragility function parameters, the fragility curves with different wind scenarios can be obtained. A threedimensional graph is used to show the fragility curves for one specified critical level with different wind speeds and PGA. Figure 11 shows the comparison of the fragility with different wind speeds between the two models for MY, ML, DY, and DL. From Figure 11(a), it is observed that the fragility increases as the wind speed increases for the same PGA in model 1 because of the increase of aerodynamic loads, and the effect of wind loads on fragility curve is insignificant when the wind speed is lower than the rated wind speed due to the small aerodynamic loads in this wind region in model 2, but the fragility of wind turbine has a significant decrease when wind speed exceeds the rated speed. It is also noted that the probability of the exceedance specified critical level MY in model 2 is larger than that in model 1 when the wind speed is around the cut-in wind speed and is less than that in model 1 when the wind speed surpasses the cut-in wind speed and the difference increases with the increase of wind speed especially in the above-rated wind speed range, and the same phenomenon occurs in the critical levels ML, DY, and DL. The results depict that when considering the coupling of seismic and aerodynamic loads, the 


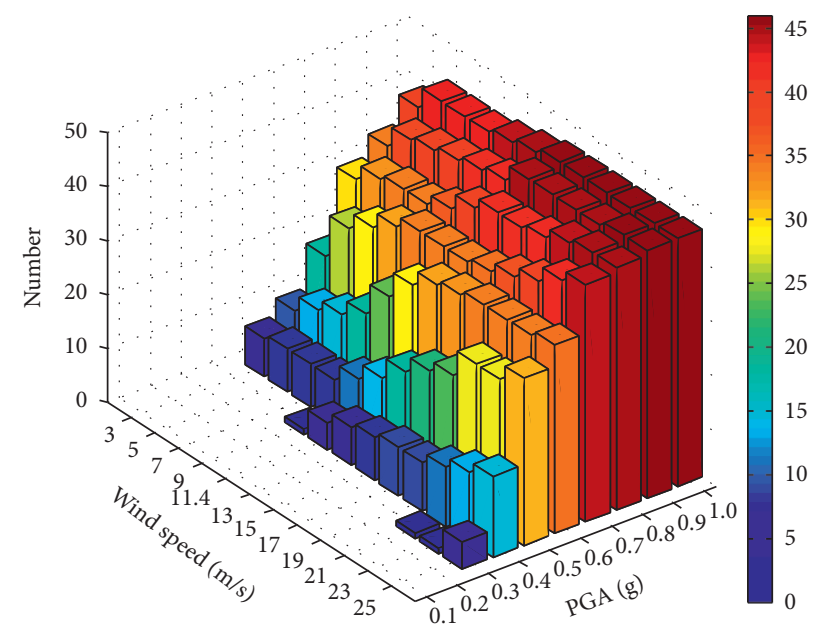

(a)

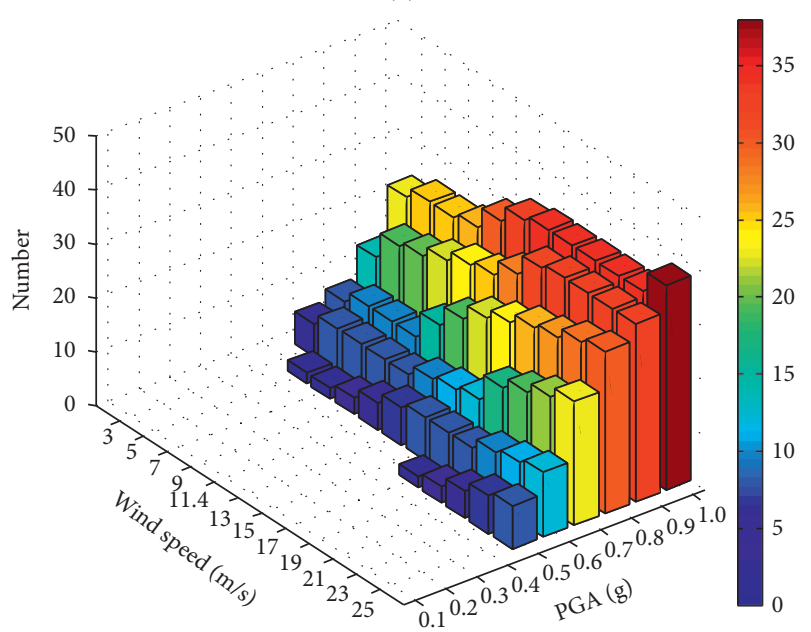

(c)

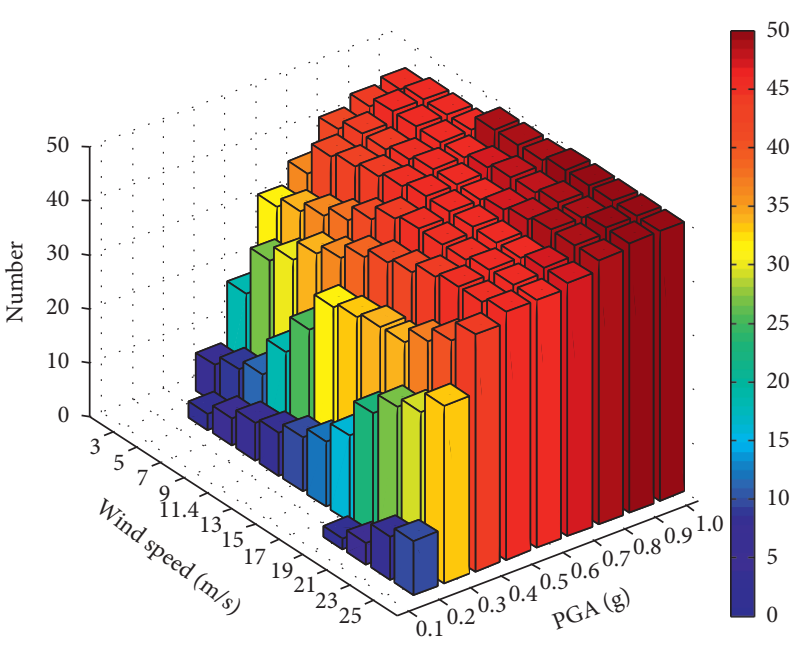

(b)

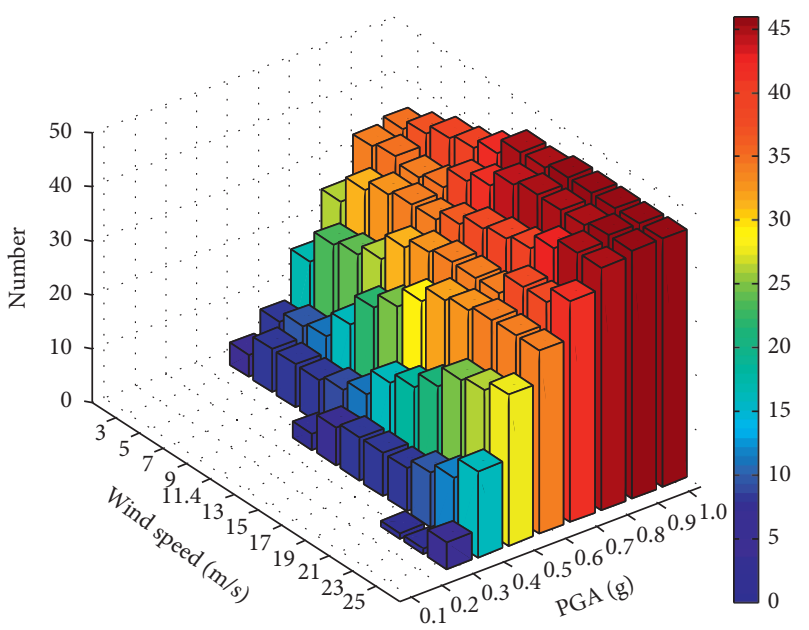

(d)

FIgURE 7: The number of exceeding specified critical levels for different wind speeds and PGA in model 1: (a) MY, (b) ML, (c) DY, and (d) DL.

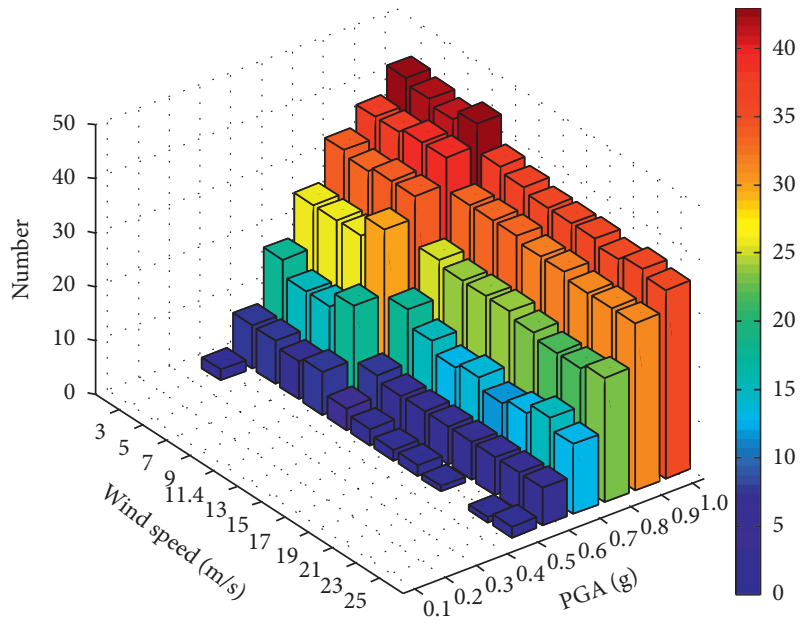

(a)

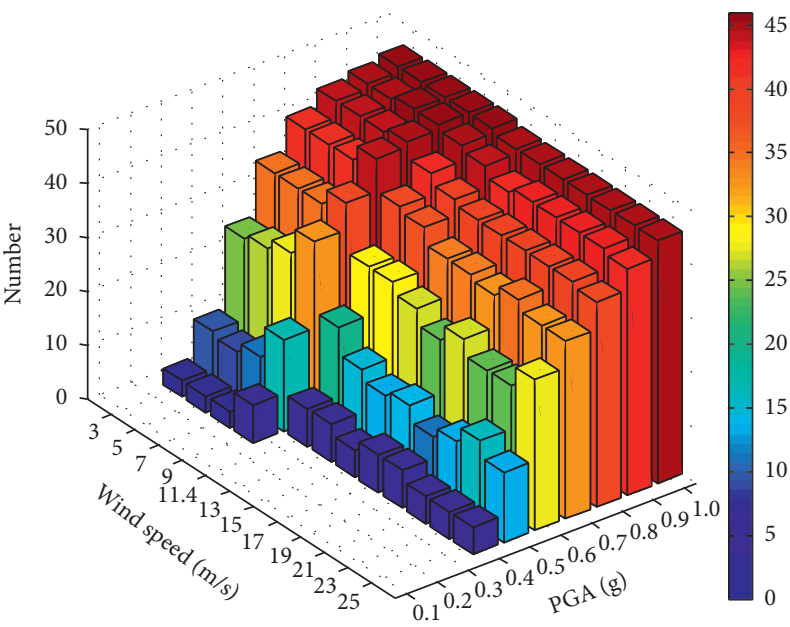

(b)

Figure 8: Continued. 


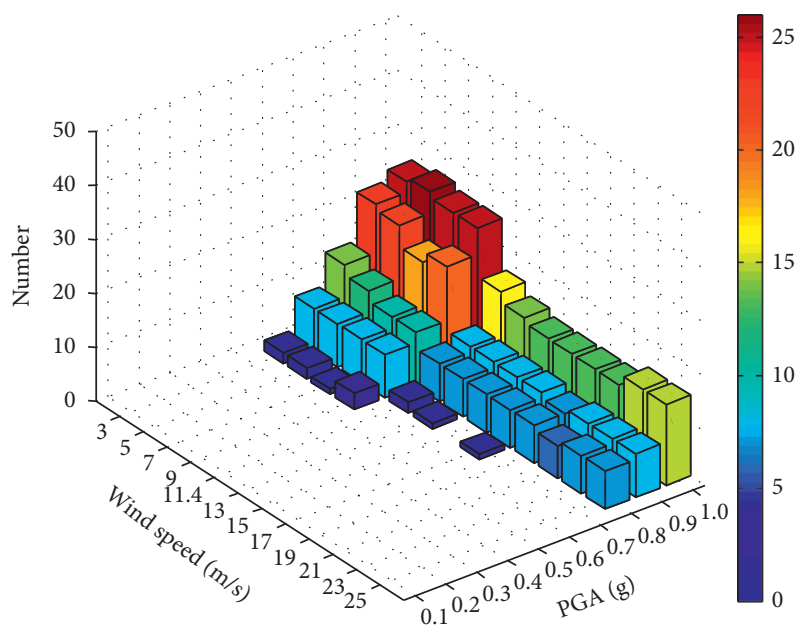

(c)

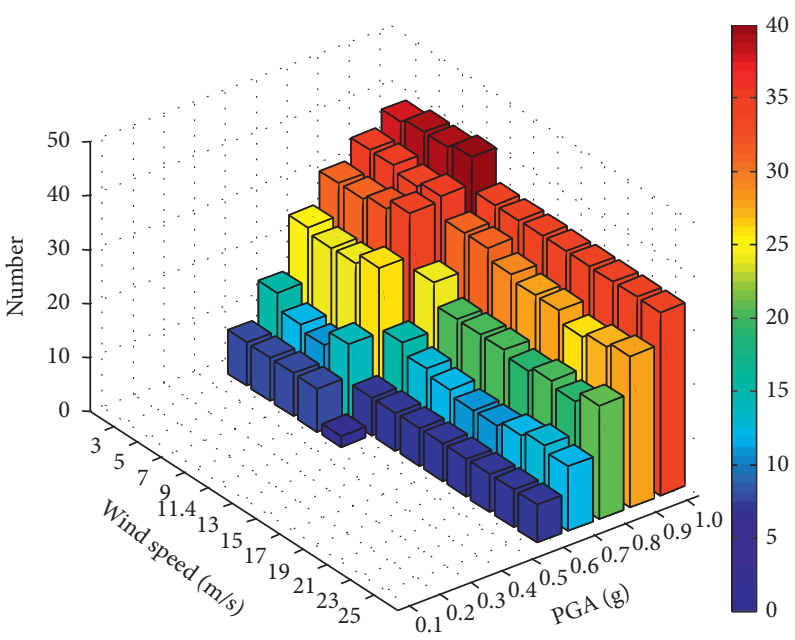

(d)

Figure 8: The number of exceeding specified critical levels for different wind speeds and PGA in model 2: (a) MY, (b) ML, (c) DY, and (d) DL.

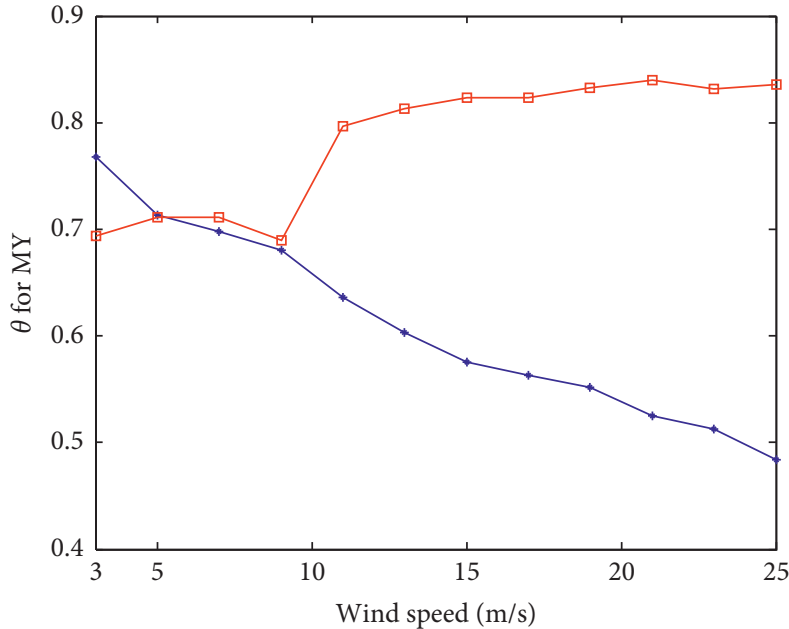

$\rightarrow$ Model 1

$\square$ Model 2

(a)

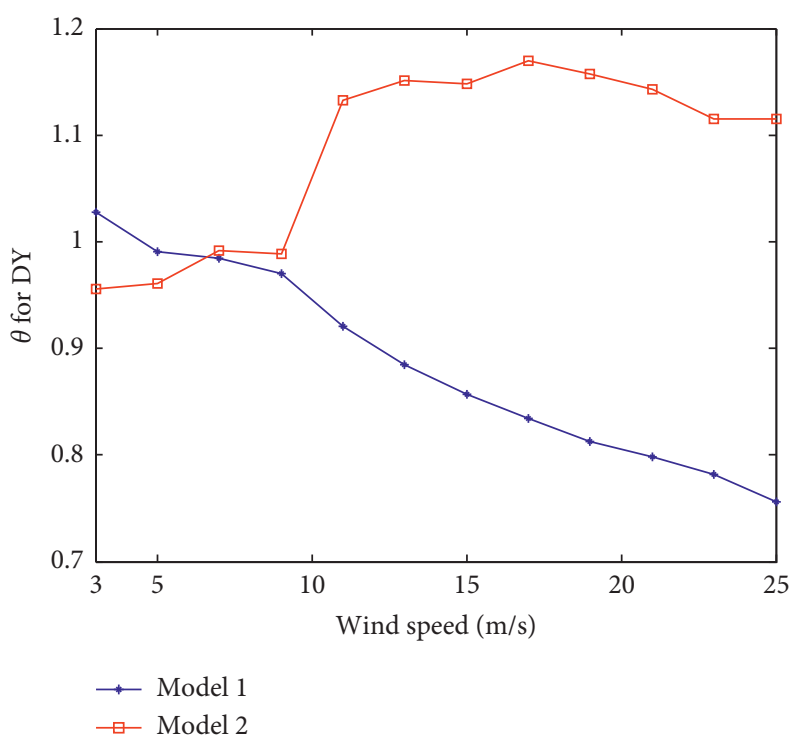

(c)

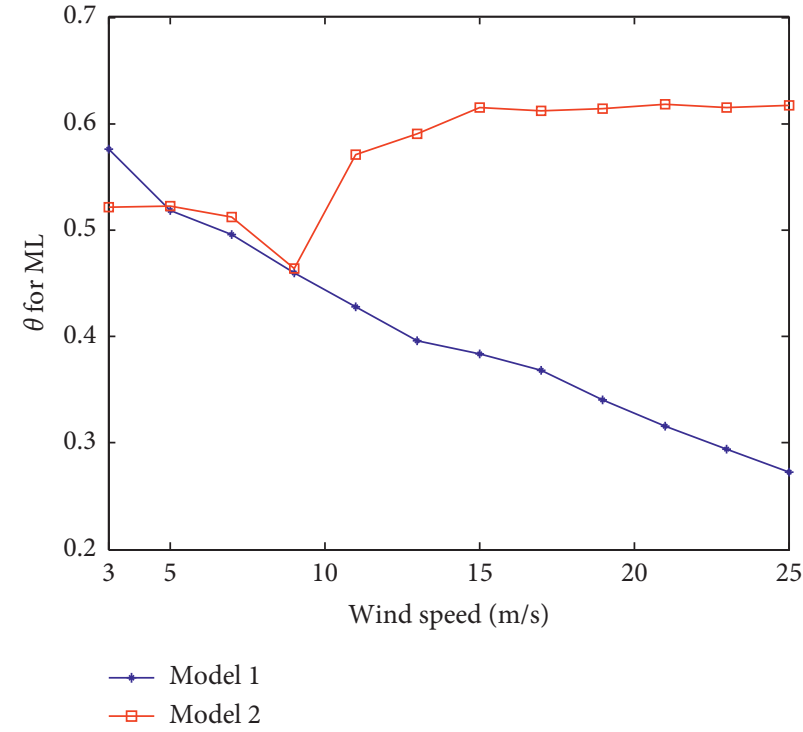

(b)

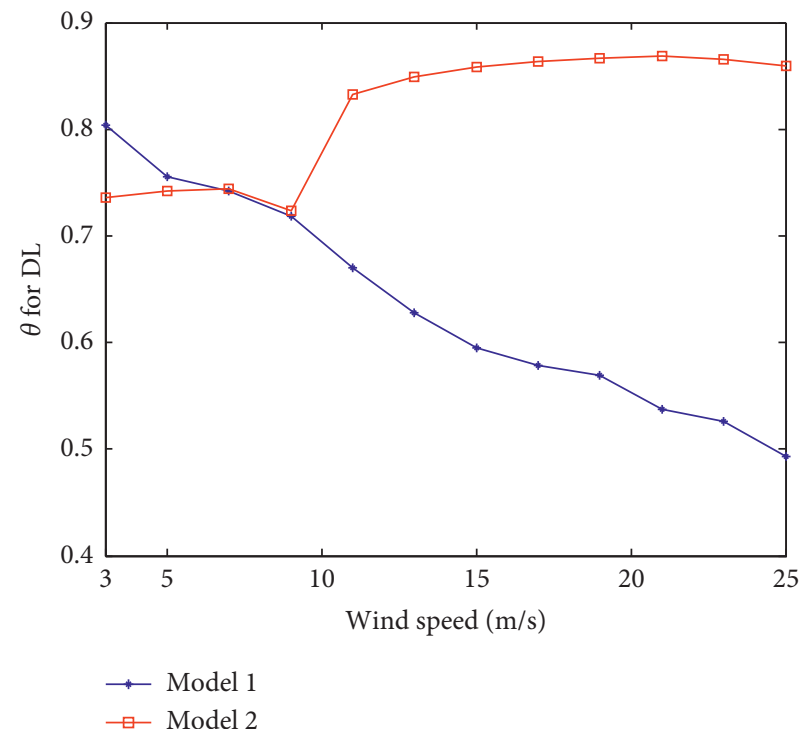

(d)

Figure 9: Comparison of the estimated $\theta$ with different wind speeds between the two models: (a) MY, (b) ML, (c) DY, and (d) DL. 


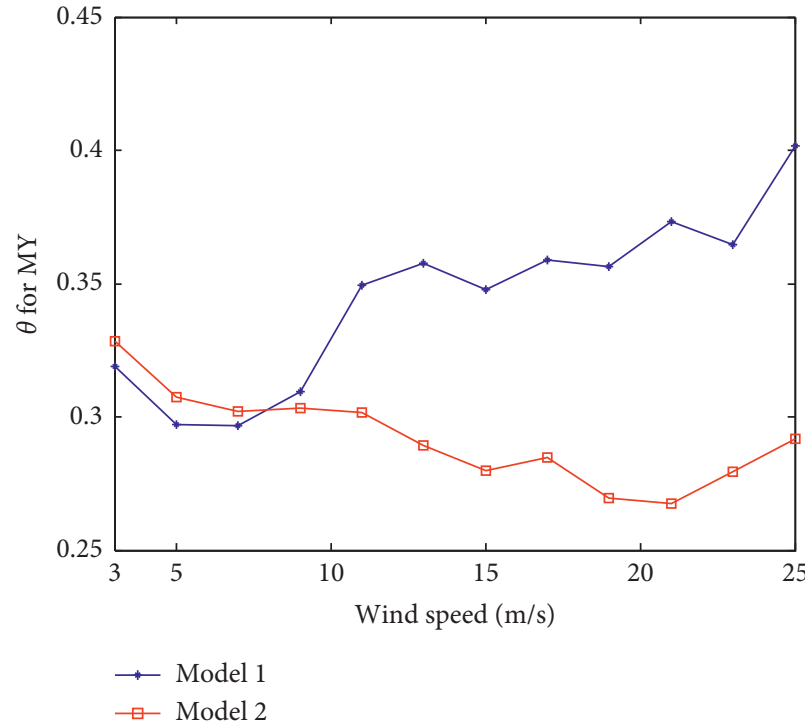

(a)

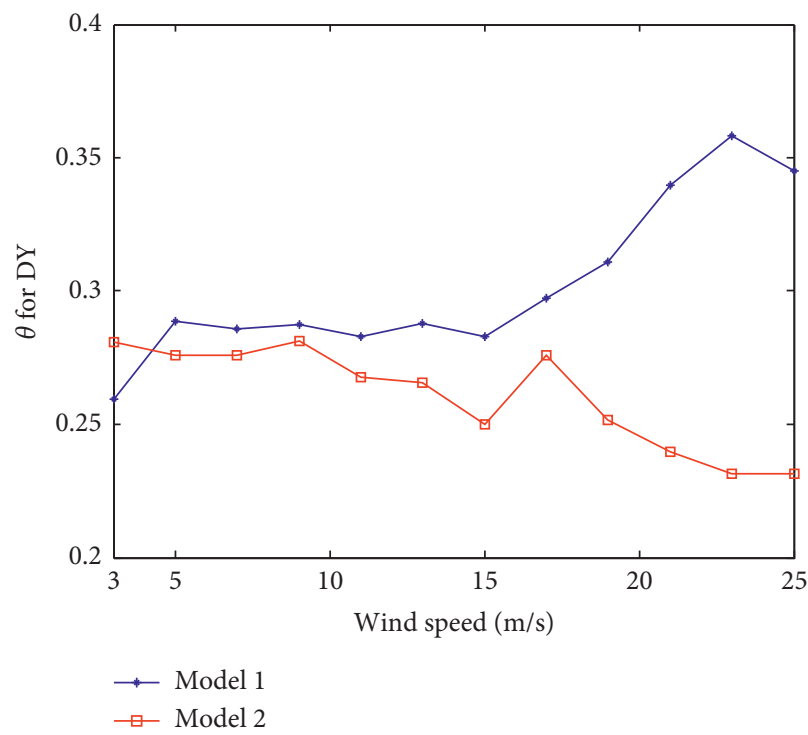

(c)

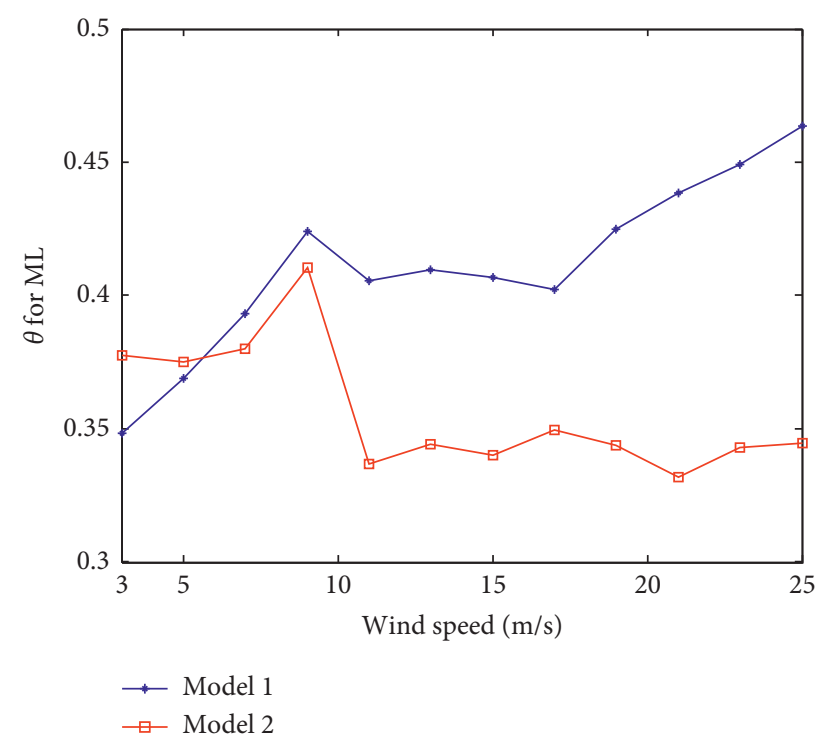

(b)

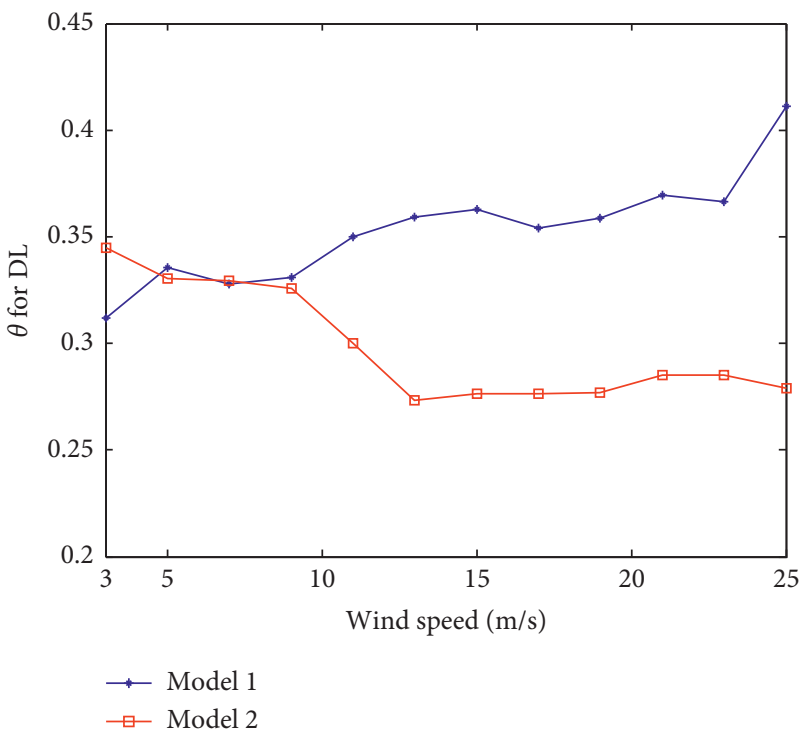

(d)

Figure 10: Comparison of the estimated $\beta$ with different wind speeds between the two models: (a) MY, (b) ML, (c) DY, and (d) DL.

model 1 will underestimate the fragility of wind turbine in around cut-in wind speed range and overestimate the fragility of wind turbine in exceeding cut-in and especially the over-rated wind speed range compared to that in model 2. It can be concluded that the BCS has a great effect on the fragility of wind turbine when the coupling of earthquake and aerodynamic loads is considered, especially for the conditions of surpassing the rated wind speed.

\section{Conclusions}

This study focuses on two computational models for fragility analysis of large-scale wind turbine subjected to the coupling of seismic and aerodynamic loads to study the influence of BCS on the fragility of wind turbines. The rotor speed and blade-pitch angle are fixed in model 1 and keep changing according to the BCS in model 2. The major difference between the two models is whether the control system for power output is considered or not. The basic control process of BCS is given to show the way of regulating the rotor speed and blade-pitch angle.

A set of 12 wind files with different $V_{\text {hub }}$ from $3 \mathrm{~m} / \mathrm{s}$ to $25 \mathrm{~m} / \mathrm{s}$ wind speed are generated. Fifty ground motions are selected and spectrally matched with the design spectra. The developed FAST program was used to obtain the dynamic responses of a $5 \mathrm{MW}$ wind turbine with the interaction of aerodynamic and seismic loads. The number of exceedance specified critical levels for different wind speeds and PGA in the two models was given as a three-dimensional histogram. 


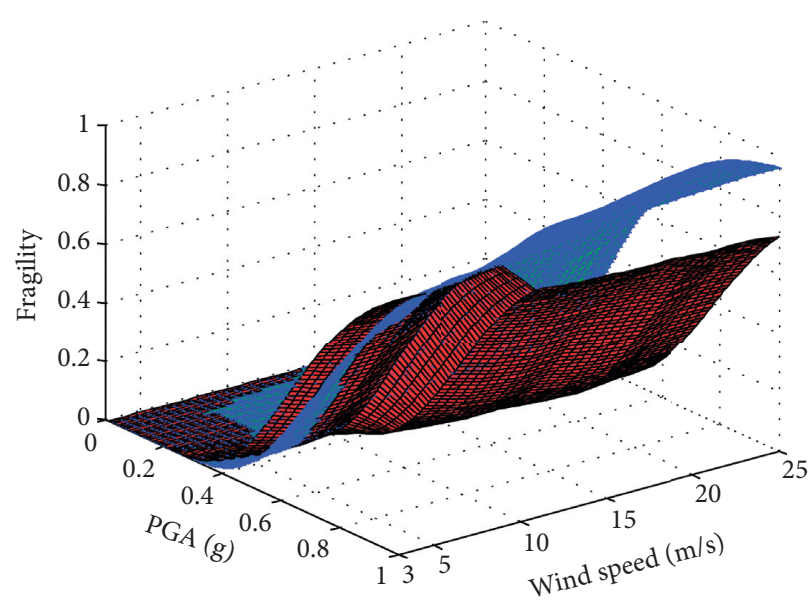

Model 1

Model 2

(a)

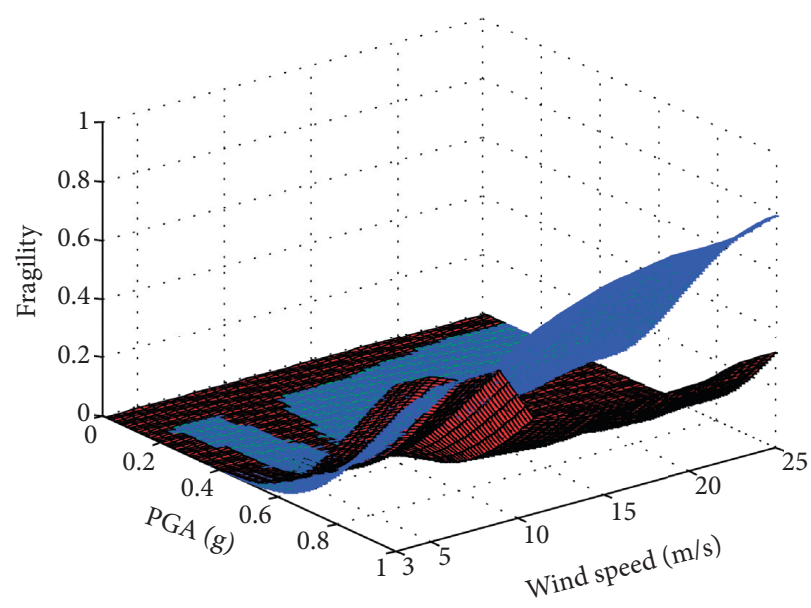

Model 1

Model 2

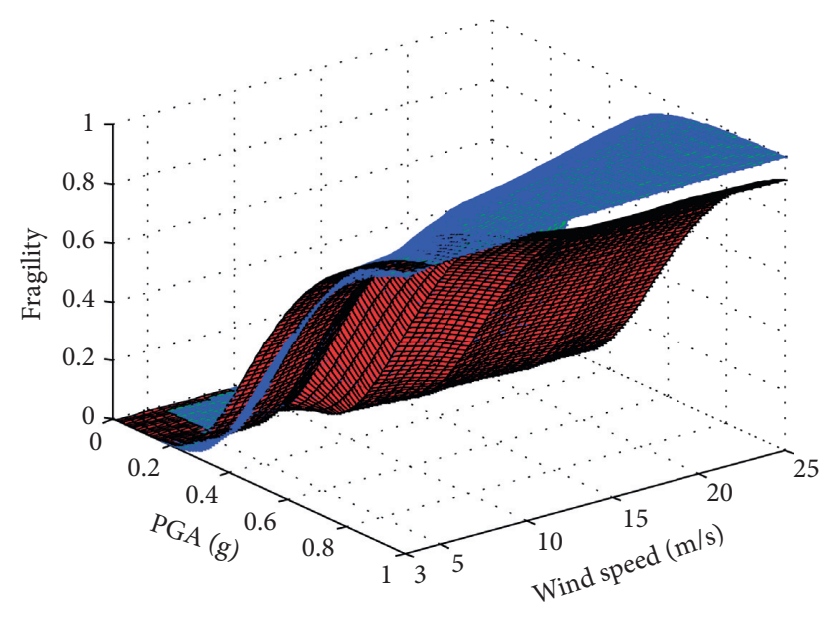

Model 1

Model 2

(b)

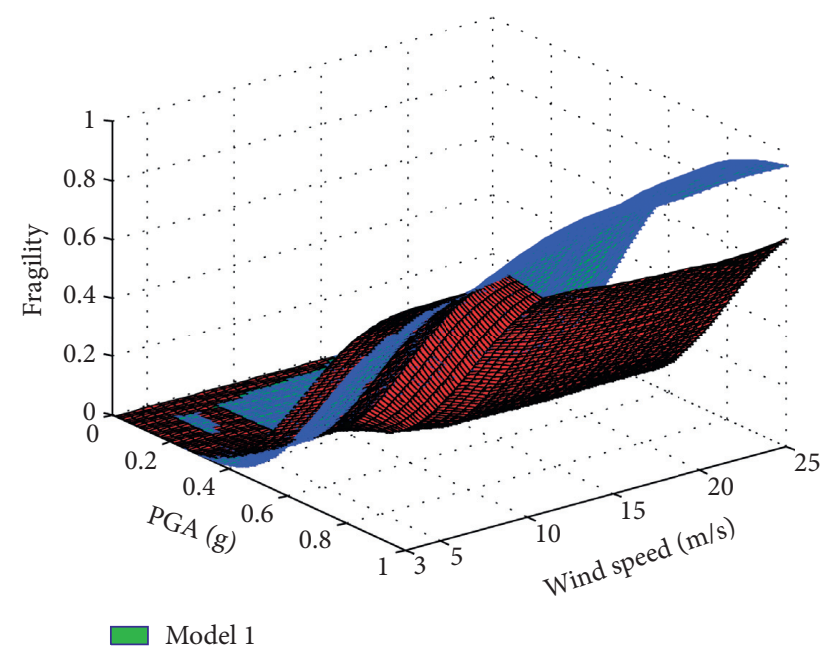

Model 2

(c)

(d)

Figure 11: Comparison of the fragility with different wind speeds between the two models: (a) MY, (b) ML, (c) DY, and (d) DL.

By comparing the exceeded number in each wind and PGA level between the two models, it is concluded that the BCS has an obvious influence on the results of dynamic responses especially in the above-rated wind speed range. The MSA method was used to estimate the related fragility function parameters. By comparing the estimated fragility function parameters in the two models, it indicated that the difference in the coupling effect of seismic and aerodynamic loads results in the obvious difference of the estimated values of the $\theta$ and $\beta$. The fragility curves were given in a threedimensional graph for different wind speeds and PGA with the four specified critical levels and compared between the two models. It was shown that the fragility in model 2 is larger than that in model 1 when the wind speed is around cut-in wind speed and is less than that in model 1 when the wind speed exceeds the cut-in wind speed especially in the above-rated wind speed range. It indicated that the control system has a great effect on the fragility of wind turbine subjected to the coupling of earthquake and aerodynamic load especially when the wind speed exceeds the rated wind speed. As a result, the computational model 2 with considering BCS is more accurate than model 1 when estimating the fragility of wind turbine subjected to seismic and aerodynamic loads. As the reliability evaluation of largescale wind turbines under external loads becomes more and more important, future research efforts can be focused on a more precise assessment of reliability, such as elaborate wind turbine model and the uncertainty of environmental loads.

\section{Data Availability}

The data used to support the findings of this study are available from the corresponding author upon request.

\section{Conflicts of Interest}

There are no conflicts of interest regarding the theoretical and numerical observations introduced in this paper. 


\section{Acknowledgments}

This research was funded by the National Key Research and Development Project (grant no. 2018YFC0406901), National Natural Science Foundation of China (grant nos. 51179026 and 51679092), and Scientific Research Project of North China University of Water Resources and Electric Power (grant no. 201811007). The authors gratefully acknowledge the enthusiastic help of Dr. Jason Jonkman.

\section{References}

[1] Global Wind Energy Council, Global Wind Report 2018, GWEC, Brussels, Belgium, 2019.

[2] International Electrotechnical Commission, Wind Energy Generation Systems-Part 1: Design Requirements, International Electrotechnical Commission, Geneva, Switzerland, 2019.

[3] M. O. L. Hansen, Aerodynamics of Wind Turbines, Earthscan, London, UK, Second edition, 2008.

[4] S. Naguleswaran, "Lateral vibration of a centrifugally tensioned uniform Euler-Bernoulli beam," Journal of Sound and Vibration, vol. 176, no. 5, pp. 613-624, 1994.

[5] I. Lavassas, G. Nikolaidis, P. Zervas, E. Efthimiou, I. N. Doudoumis, and C. C. Baniotopoulos, "Analysis and design of the prototype of a steel 1-MW wind turbine tower," Engineering Structures, vol. 25, no. 8, pp. 1097-1106, 2003.

[6] J. Li, J. Chen, and X. Chen, "Aerodynamic response analysis of wind turbines," Journal of Mechanical Science and Technology, vol. 25, pp. 89-95, 2010.

[7] P. J. Murtagh, B. Basu, and B. M. Broderick, "Along-wind response of a wind turbine tower with blade coupling subjected to rotationally sampled wind loading," Engineering Structures, vol. 27, no. 8, pp. 1209-1219, 2005.

[8] X.-B. Chen, J. Li, and J.-Y. Chen, "Wind-induced response analysis of a wind turbine tower including the blade-tower coupling effect," Journal of Zhejiang University-SCIENCE A, vol. 10, no. 11, pp. 1573-1580, 2009.

[9] C. G. Gebhardt and B. A. Roccia, "Non-linear aeroelasticity: an approach to compute the response of three-blade largescale horizontal-axis wind turbines," Renewable Energy, vol. 66, pp. 495-514, 2014.

[10] A. M. Page, G. Grimstad, G. R. Eiksund, and H. P. Jostad, “A macro-element pile foundation model for integrated analyses of monopile-based offshore wind turbines," Ocean Engineering, vol. 167, pp. 23-35, 2018.

[11] A. Staino and B. Basu, "Dynamics and control of vibrations in wind turbines with variable rotor speed," Engineering Structures, vol. 56, pp. 58-67, 2013.

[12] I. Prowell and P. Veers, "Assessment of wind turbine seismic risk: existing literature and simple study of tower moment demand," Sandia Report, vol. 3, 2009.

[13] I. Prowell, M. Veletzos, A. Elgamal, and J. Restrepo, "Experimental and numerical seismic response of a $65 \mathrm{~kW}$ wind turbine," Journal of Earthquake Engineering, vol. 13, no. 8, pp. 1172-1190, 2009.

[14] H. Qin, M. Liu, Y. Wang, J. Zhao, and X. Zeng, China: An Emerging Offshore Wind Development Hotspot with a New Assessment of China's Offshore Wind Potential, p. 64, WWF, CWEA and Sun-Yet-Sen University, Beijing, China, 2010.

[15] A. M. Avossa, C. Demartino, and F. Ricciardelli, "Assessment of the peak response of a 5MW HAWT under combined wind and seismic induced loads," The Open Construction and Building Technology Journal, vol. 11, no. 1, pp. 441-457, 2017.

[16] I. Prowell, M. Veletzos, A. Elgamal, and J. Restrepo, "Shake table test of a $65 \mathrm{~kW}$ wind turbine and computational simulation," in Proceedings of the 14th World Conference on Earthquake Engineering, IAEE, Beijing, China, pp. 12-17, October 2008.

[17] F. Santangelo, G. Failla, A. Santini, and F. Arena, "Timedomain uncoupled analyses for seismic assessment of landbased wind turbines," Engineering Structures, vol. 123, pp. 275-299, 2016.

[18] X. Wang, X. Zeng, X. Yang, and J. Li, "Seismic response of offshore wind turbine with hybrid monopile foundation based on centrifuge modelling," Applied Energy, vol. 235, pp. 1335-1350, 2019.

[19] P. Wang, M. Zhao, X. Du, J. Liu, and C. Xu, "Wind, wave and earthquake responses of offshore wind turbine on monopile foundation in clay," Soil Dynamics and Earthquake Engineering, vol. 113, pp. 47-57, 2018.

[20] M. A. Asareh and I. Prowell, "A simplified approach for implicitly considering aerodynamics in the seismic response of utility scale wind turbines," in Proceedings of the Structural Dynamics and Materials Conference, April 2012.

[21] M.-A. Asareh, W. Schonberg, and J. Volz, "Effects of seismic and aerodynamic load interaction on structural dynamic response of multi-megawatt utility scale horizontal axis wind turbines," Renewable Energy, vol. 86, pp. 49-58, 2016.

[22] M.-A. Asareh, I. Prowell, J. Volz, and W. Schonberg, "A computational platform for considering the effects of aerodynamic and seismic load combination for utility scale horizontal axis wind turbines," Earthquake Engineering and Engineering Vibration, vol. 15, no. 1, pp. 91-102, 2016.

[23] J. M. Jonkman and M. L. B. Jr, “FAST user's guide," Technical Report No NREL/EL-500-38230, National Renewable Energy Laboratory, Golden, CO, USA, 2005.

[24] M.-A. Asareh and J. S. Volz, "Evaluation of aerodynamic and seismic coupling for wind turbines using finite element approach," in Proceedings of the ASME 2013 International Mechanical Engineering Congress and Exposition, November 2013.

[25] B. Fitzgerald and B. Basu, "A monitoring system for wind turbines subjected to combined seismic and turbulent aerodynamic loads," Structural Monitoring and Maintenance, vol. 4, no. 2, pp. 175-194, 2017.

[26] A. Quilligan, A. O'Connor, and V. Pakrashi, "Fragility analysis of steel and concrete wind turbine towers," Engineering Structures, vol. 36, pp. 270-282, 2012.

[27] D. H. Kim, S. G. Lee, and I. K. Lee, "Seismic fragility analysis of $5 \mathrm{MW}$ offshore wind turbine," Renewable Energy, vol. 65, pp. 250-256, 2014.

[28] A. Patil, S. Jung, and O.-S. Kwon, "Structural performance of a parked wind turbine tower subjected to strong ground motions," Engineering Structures, vol. 120, pp. 92-102, 2016.

[29] A. F. Mensah and L. Dueñas-Osorio, "Improved reliability of wind turbine towers with tuned liquid column dampers (TLCDs)," Structural Safety, vol. 47, pp. 78-86, 2014.

[30] A. Hemmati, E. Oterkus, and N. Barltrop, "Fragility reduction of offshore wind turbines using tuned liquid column dampers," Soil Dynamics and Earthquake Engineering, vol. 125, p. 105705, 2019.

[31] B. Fitzgerald, S. Sarkar, and A. Staino, "Improved reliability of wind turbine towers with active tuned mass dampers (ATMDs)," Journal of Sound and Vibration, vol. 419, pp. 103-122, 2018. 
[32] T. Q. Do, J. W. van de Lindt, and H. Mahmoud, "Fatigue life fragilities and performance-based design of wind turbine tower base connections," Journal of Structural Engineering, vol. 141, 2014.

[33] M. Mardfekri and P. Gardoni, "Multi-hazard reliability assessment of offshore wind turbines," Wind Energy, vol. 18, no. 8, pp. 1433-1450, 2015.

[34] D. Wilkie and C. Galasso, "Site-specific ultimate limit state fragility of offshore wind turbines on monopile substructures," Engineering Structures, vol. 204, 2020.

[35] A. Avossa, C. Demartino, P. Contestabile, F. Ricciardelli, and D. Vicinanza, "Some results on the vulnerability assessment of HAWTs subjected to wind and seismic actions," Sustainability, vol. 9, no. 9, p. 1525, 2017.

[36] J. O. M. del Campo and A. Pozos-Estrada, "Multi-hazard fragility analysis for a wind turbine support structure: an application to the Southwest of Mexico," Engineering Structures, vol. 209, 2019.

[37] M.-A. Asareh, W. Schonberg, and J. Volz, "Fragility analysis of a 5-MW NREL wind turbine considering aero-elastic and seismic interaction using finite element method," Finite Elements in Analysis and Design, vol. 120, pp. 57-67, 2016.

[38] J. Jonkman, S. Butterfield, W. Musial, and G. Scott, Definition of a 5-MW Reference Wind Turbine for Offshore System Development, National Renewable Energy Laboratory, Golden, CO, USA, 2009.

[39] C. Yuan, J. Chen, J. Li, and Q. Xu, "Fragility analysis of largescale wind turbines under the combination of seismic and aerodynamic loads," Renewable Energy, vol. 113, pp. 11221134, 2017.

[40] M. Asareh and I. Prowell, "Seismic loading for FAST," Contract, vol. 303, 2011.

[41] J. Chen, C. Yuan, J. Li, and Q. Xu, "Semi-active fuzzy control of edgewise vibrations in wind turbine blades under extreme wind," Journal of Wind Engineering and Industrial Aerodynamics, vol. 147, pp. 251-261, 2015.

[42] T. Burton, N. Jenkins, D. Sharpe, and E. Bossanyi, Wind Energy Handbook, Wiley, Hoboken, NY, USA, 2011.

[43] T. R. Kane and D. A. Levinson, Dynamics, Theory and Applications, McGraw-Hill, New York, NY, USA, 1985.

[44] I. Prowell, A. Elgamal, and J. M. Jonkman, FAST Simulation of Wind Turbine Seismic Response, National Renewable Energy Laboratory, Technical Report No. NREL/CP-500-46225, 2010.

[45] A. Wright and L. Fingersh, Advanced Control Design for Wind Turbines. Part I: Control Design, Implementation, and Initial Tests, National Renewable Energy Laboratory, Golden, CO, USA, 2008.

[46] M. H. Hansen, A. Hansen, T. J. Larsen, S. Фye, Sørensen, and P. Fuglsang, Control Design for a Pitch-Regulated, VariableSpeed Wind Turbine, Risø-R-1500(EN), Risø National Laboratory, Roskilde, Denmark, 2005.

[47] D. Vamvatsikos and C. A. Cornell, "Incremental dynamic analysis," Earthquake Engineering \& Structural Dynamics, vol. 31, no. 3, pp. 491-514, 2002.

[48] J. W. Baker, "Efficient analytical fragility function fitting using dynamic structural analysis," Earthquake Spectra, vol. 31, no. 1, pp. 579-599, 2015.

[49] B. J. Jonkman and L. Kilcher, TurbSim User's Guide: Version 1.06. 00, National Renewable Energy Laboratory, Golden, CO, USA, 2012.

[50] China PsRo, Code for Seismic Design of Buildings, China Architecture \& Building Press, Beijing, China, 2010.

[51] A. S. Elnashai and L. Di Sarno, Fundamentals of Earthquake Engineering, Wiley, Chichester, UK, 2008.
[52] http://peer.berkeley.edu.

[53] J. Hancock, J. J. Bommer, and P. J. Stafford, "Numbers of scaled and matched accelerograms required for inelastic dynamic analyses," Earthquake Engineering \& Structural Dynamics, vol. 37, no. 14, pp. 1585-1607, 2008.

[54] Engineers ASoC, Minimum Design Loads for Buildings and Other Structures, ASCE, Reston, VA, USA, 2010.

[55] Seismo Soft, "Seismo match V. 2.1.2, software," 2016, http:// www.seismosoft.com.

[56] R. Mo, H. Kang, M. Li, and X. Zhao, "Seismic fragility analysis of monopile offshore wind turbines under different operational conditions," Energies, vol. 10, no. 7, p. 1037, 2017.

[57] F. Jalayer, Direct Probabilistic Seismic Analysis: Implementing Non-linear Dynamic Assessments, Stanford University, Stanford, CA, USA, 2003. 